\title{
Breaking the silence: Learning about youth sexual and reproductive health in Egypt
}

Nahla G. Abdel-Tawab

Population Council

Sally Saher

Population Council

Nora El Nawawi

Follow this and additional works at: https://knowledgecommons.popcouncil.org/departments_sbsr-pgy

Part of the Demography, Population, and Ecology Commons, Family, Life Course, and Society Commons, Gender and Sexuality Commons, and the International Public Health Commons How does access to this work benefit you? Let us know!

\section{Recommended Citation}

Abdel-Tawab, Nahla G., Sally Saher, and Nora El Nawawi. 2013. "Breaking the silence: Learning about youth sexual and reproductive health in Egypt." Cairo: Population Council. 


\section{BREAKING THE SILENCE: LEARNING ABOUT YOUTH SEXUAL AND REPRODUCTIVE HEALTH IN EGYPT}

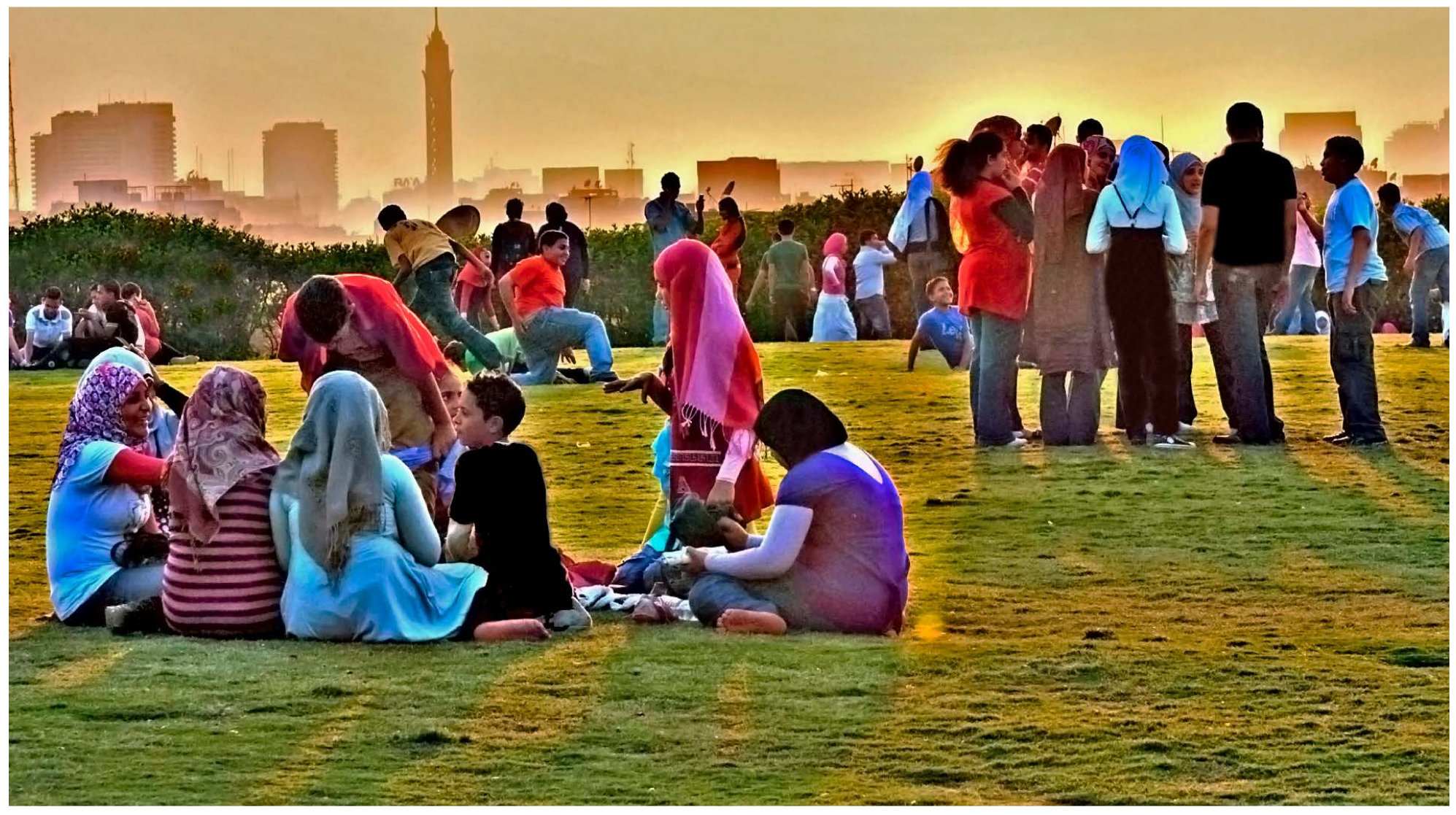

NAHLA ABDEL-TAWAB SALLY SAHER NORA EL NAWAWI EDITORS 


\title{
(2) Population Council
}

The Population Council confronts critical health and development issues-from stopping the spread of HIV to improving reproductive health and ensuring that young people lead full and productive lives. Through biomedical, social science, and public health research in 50 countries, we work with our partners to deliver solutions that lead to more effective policies, programmes, and technologies that improve lives around the world. Established in 1952 and headquartered in New York, the Council is a nongovernmental, nonprofit organisation governed by an international board of trustees.

\author{
Population Council \\ One Dag Hammarskjold Plaza \\ New York, NY 10017 \\ Population Council \\ 59 Misr-Helwan Agricultural Road, Maadi \\ PO Box 168, Maadi \\ Cairo, EGYPT \\ 11431 \\ Tel: +20 225255967 \\ Fax: +20 225255962
}

www.popcouncil.org

Suggested citation: Nahla Abdel-Tawab, Sally Saher, and Nora El Nawawi (editors). 2013. "Breaking the Silence: Learning about Youth Sexual and Reproductive Health in Egypt." Cairo: Population Council.

(C) 2013 The Population Council, Inc. 


\section{TABLE OF CONTENTS}

Acknowledgments/Project Team

Foreword

1 Overview: Building Capacity to Conduct Research on Youth Sexual and Reproductive Health in Egypt........1 NAHLA ABDEL-TAWAB YASMINE YOUSRI AND HEBA M. MAMDOUH

A Survey of Father-Son Communication Concerning Sexual and Reproductive Health in Sharkiya, Egypt HAYTHAM MAHMOUD HASSAN

Sexual and Reproductive Health Education in Egyptian Schools: The Ideal and the Reality .21 FATMA EL ZAHRAA GEEL

5 Youth-Friendly Clinics: Exploring Egyptian Provider Attitudes and Communication Behaviors about Sexual and Reproductive Health HALA EL DAMANHOURY AND DALIA ABDELHAMEED

Sexual and Reproductive Health Experiences of Married Adolescent Girls in Rural Upper Egypt. 35 MANAL DARWISH, WAFAA HAMZA, MIRETTE AZIZ, AND AMIRA EL-GAZZAR

7 "If She Is Respectable, No One Will Harm Her": Attitudes of Egyptian Young Men toward Sexual Harassment of Women.

MONA HASSAN, OMNIA MEHANNA, AND ALAA SAMRA

\section{TABLES}

2.1 Socio-demographic characteristics of participating mothers 9

3.1 Socio-demographic characteristics of participating fathers

3.2 Logistic regression analysis of occupational, knowledge, and attitudinal factors associated with father-son communication about SRH.

5.1 Demographic and occupational characteristics of providers in Youth Friendly Clinics

6.1 Socio-demographic characteristics of married adolescent girls

\section{FIGURES}

3.1 Fathers' knowledge of physical and emotional changes associated with puberty

3.2 Fathers' attitudes about female genital mutilation 


\section{ACKNOWLEDGMENTS}

Many individuals contributed to this volume of papers on youth sexual and reproductive health in Egypt. The researchers who completed these innovative studies deserve our special thanks and admiration. Through their work, they have enhanced our understanding of the needs of young people and have provided direction for future research. We are deeply grateful to the young people, parents, teachers, health care providers, and government officials who shared their views and experiences in this sensitive area.

The Advisory Group for this project provided helpful suggestions in all phases of the project and was instrumental in guiding the researchers to push the boundaries, while maintaining social and cultural appropriateness. This project would not have been possible without the generous funds of the Ford Foundation. Special thanks go to Montasser Kamal, senior reproductive health program officer, for his invaluable support and encouragement throughout this project and his keen interest in breaking new ground to enhance youth sexual and reproductive health.

We envision this volume as a starting point for many who are seeking ways to help young people gain better access to sexual and reproductive health information and services. We remain hopeful that these findings will encourage more researchers to "break the silence" and more policymakers to "take the risk" of helping young people make healthy transitions to adulthood.

\section{PROJECT TEAM}

\section{Population Council Team}

Nahla Abdel-Tawab, Principal Investigator

Sally Saher, Project Coordinator

Gihan Hosny, Project Administrator

\section{Advisory Group}

Soha Abdel-Aty, Deputy Director, Egyptian Initiative for Personal Rights

Maisa El-Mofty, Professor of Psychology, Ain Shams University

Mawaheb El-Mouelhy, Reproductive Health Consultant

Ahmed Ragai, Professor of Reproductive Health, Al-Azhar University

Sanaa Refaat, Professor of Histology, Faculty of Women, Ain Shams University

Mamdouh Wahba, President, Egyptian Family Health Society

\section{Reviewers}

Maha El-Rabbat, Professor of Public Health, Cairo University

Nora El-Nawawi, Independent Consultant

Sarah Ismail, Independent Consultant 


\section{FOREWORD}

Sexuality and reproduction are among the most fundamental aspects of life, but because of cultural and political sensitivities they often receive little attention in public policy discussions. Thus it is very encouraging to see this important collection of research (generously supported by the Ford Foundation office in Cairo) and the Population Council's efforts to build the capacity of young Egyptian researchers to study youth sexual and reproductive health. Reports such as this can help shed light on these intimate and sensitive topics, encourage scientific debates, and highlight means of improving the sexual and reproductive health of young people in Egypt.

Sexual and reproductive health is an important aspect of individuals' lives and a country's development. The goal of ensuring universal access to sexual and reproductive health information and services was first articulated at the United Nations International Conference on Population and Development (ICPD), held in Cairo in 1994. The ICPD's “Programme of Action" was precedent-setting in making women's rights and reproductive health central to social and economic development, and in addressing the reproductive health needs of young people. "Universal access to reproductive health" is a target of the Millennium Development Goals, which were outlined by world leaders in the year 2000 to combat poverty, hunger, disease, illiteracy, environmental degradation, and discrimination against women.

The Population Council has been a pioneer in research on the medical and social aspects of sexual and reproductive health issues in Egypt and beyond. The Council's well-known Giza Morbidity Study, conducted in the late 1980s in a rural community of Egypt's Giza Governorate, was the first scientific and multidisciplinary research in the Middle East region to reveal the heavy burden of poor health women bear as a consequence of sexual and reproductive health conditions. The study made the invisible suffering of Egyptian women from reproductive illnesses visible and opened doors for Egyptian researchers who wanted to study sexual and reproductive health issues.
I foresee that the body of current pioneering research could have a similar effect, encouraging Egyptian researchers to implement research they may not have previously considered, moving beyond the topics covered in this report to study all aspects of youth sexual and reproductive health. Sexual and reproductive knowledge and decisions, and their consequences, are experienced by individuals but are shaped by factors within the household, community, larger society, and political environment.

Decision-makers in Egypt must be provided with accurate and comprehensive data and analysis on youth sexual and reproductive health. To this end, a number of things need to take place. The capacity of Egyptian institutions needs to be strengthened so that sound research on youth sexual and reproductive health issues can be conducted, and researchers must overcome their biases and ask the right research questions without restrictions. Also, the results must be made available in a timely manner and in formats that policymakers, program managers, and the public at large can understand. Finally, Egyptian policymakers and program managers need to make better use of the information as evidence for policy change and program improvements.

This report is timely, setting the stage for the enormous work ahead in meeting young people's needs for reliable sexual and reproductive health information and youth-friendly health services. In the next 15 years, 26 million Egyptians will reach the age of 15, according to the United Nations Population Division. And, today, one in five Egyptians is between the ages of 15 and 24 . These young people are at a crucial juncture in their lives. They must be given accurate information and access to services to protect their sexual and reproductive health and to prepare them for taking on family responsibilities as they get older. 
Finally, Egypt has entered a new era and the demands of its young people cannot be ignored. Young people enthusiastically led the Revolution of 25 January, calling for changes that could help them meet their basic needs and fulfill their aspirations for freedom and a better life. Understanding the needs of young Egyptians, including their sexual and reproductive health needs, is crucial for developing policies and programs that can help bring about desired changes and improve their health and well-being. This report is a small but an important step toward a better understanding of young people's sexual and reproductive health needs in Egypt.

FARZANEH (NAZY) ROUDI

Program Director for the Middle East and North Africa Region

Population Reference Bureau 


\title{
OVERVIEW: BUILDING CAPACITY TO CONDUCT
RESEARCH ON YOUTH SEXUAL AND REPRODUCTIVE
HEALTH IN EGYPT
}

\author{
NAHLA ABDEL-TAWAB*
}

\section{INTRODUCTION}

Every once in a while Egyptian mass media highlights a sensational issue related to youth sexual and reproductive health (SRH) and calls for immediate action from policymakers. The latter are often caught in the cross fire and turn to researchers for answers to questions such as, "Can those figures be true?" "Which groups are most likely to suffer from those problems?" "What are the underlying causes?" "Are there any solutions that have proven effective?" Unfortunately, researchers rarely have answers to these questions, because research tackling youth SRH issues in Egypt barely exists.

Despite worldwide recognition of the importance of youth $\mathrm{SRH}$ as an integral component of overall health and wellbeing, research in this arena remains sparse in Egypt. Young people 10-29 years of age account for more than 40 percent of the country's population (Population Council 2011). Despite the growing numbers of adolescents and youth in Egypt and their potential exposure to high-risk behaviors, little is known about their knowledge or practices in relation to $\mathrm{SRH}$. A Pubmed search showed that from 1994 to 2010, only 93 studies on sexual health in Egypt were published in the peer-reviewed literature. In contrast, 763 Egyptian studies had been published in other areas of health, such as hepatitis, during the same time period.

The lack of research on youth SRH is largely due to social and cultural norms wherein topics related to sexuality are considered private matters that should not be discussed in public (Parker 2009). This culture of silence has impacted researchers, potential research participants, and government authorities. Many researchers and their academic supervisors are not aware of salient issues in youth SRH and hence do not consider it a research priority. Others may refrain from studying certain topics or behaviors that conflict with their own
"There are 20,000 cases of sexual harassment / assault that take place in Egypt every year."

-AL-AHRAM, 2 JUNE 2013

"Thirty percent of divorces in Egypt are due to sexual problems."

-AL-AHRAM, 30 AUGUST 2011

"One in ten university students

in Egypt is involved in an Urfi marriage."

-AL-AHRAM, 29 MAY 2007

personal values. Some researchers fear being stigmatized by colleagues for studying certain topics (e.g., homosexuality), while fear of negative reactions by research participants or communities may deter other researchers from asking sensitive questions (Al-Shdayfat and Green 2011). The above factors have not only had a negative impact on researchers but have also deterred government authorities and academic research committees from granting permits to enable researchers to conduct fieldwork on such topics. There is widespread belief that talking openly about sex might encourage unmarried youth to engage in premarital sexual relations (DeJong and El-Khoury 2006). Likewise, many donor agencies have opted to stay away from studying youth $\mathrm{SRH}$, perhaps

\footnotetext{
* Nahla Abdel-Tawab is Senior Associate at the Population Council, Egypt. E-mail: ntawab@popcouncil.org.
} 
due to restrictions posed by their own governments or to avoid conflict with local authorities.

Given that one in five Egyptians (or nearly 16 million people) are between the ages of 15 and 24, the need to study youth SRH cannot be overemphasized (United Nations Population Division 2011). This age group, referred to as "youth," is at the critical stage where they undergo many biological, psychological, and social changes (Roudi-Fahimi and El Feki 2011). The extent to which this large group of young people will become healthy and productive members of society depends on how well the Egyptian government and civil society invest in social, economic, and political institutions that meet the current needs of young people (Assaad and Roudi-Fahimi 2007).

As in many parts of the world, youth in Egypt face a number of SRH risks. As a result of recent socioeconomic developments, young men and women stay in school longer and delay marriage. During this relatively long transitional period between childhood and adulthood, young people may have sexual relationships before marriage, putting them at risk of stigmatization, sexually transmitted infections, unintended pregnancies, unsafe abortions, and more (Roudi-Fahimi and El Feki 2011). At the other end of the spectrum are girls who are still marrying at a young age. The 2009 Survey of Young People in Egypt has shown that 42 percent of married women aged 18-24 in rural Upper Egypt were married before age 18 (Population Council 2011). Early marriage poses significant risks to the health and well-being of young women, including complications of early pregnancy, gender-based violence, and sexually transmitted infections, especially if these girls are married to men who are much older than they are (Bruce 2003).

In addition to these two groups, millions of young men and women have unanswered questions and unresolved problems related to their sexual and reproductive health. Some want to know such things as what changes to expect in their bodies during puberty, or if masturbation will make them infertile, or if the hymen can break while playing sports (Wahba 2011). These and many other questions are disturbing for young people, but they often go unanswered because of lack of access to reliable sources of reproductive health $(\mathrm{RH})$ information and services.

As in every field, research plays a cardinal role in identifying and overcoming social and economic disparities and health system inadequacies that prevent us from reaching the highest attainable standard of SRH for all (Global Forum for Health Research and World Health Organization 2007). This lack of sound, reliable information and the scarcity of scientific knowledge relevant to youth SRH in Egypt only exacerbate the challenges in addressing those issues and their implications for the health and well-being of youth and the society as a whole. It is of utmost importance to have an accurate database upon which appropriate policies and interventions pertaining to youth SRH can be formulated. Understanding young people's perspectives and needs is key to informing legislation, policy, and programs (DeJong and El-Khoury 2006).

\section{A PROJECT TO BUILD RESEARCH CAPACITY}

To fill this knowledge gap, the Population Council in Cairo, with funds from the Ford Foundation, implemented a project to build the capacity of junior researchers in Egypt to conduct innovative, and methodologically and ethically sound, research on youth SRH. The project's objectives were to: (1) build a cadre of Egyptian researchers who are capable of conducting research that addresses youth $\mathrm{SRH}$ information needs and influencing policy change, and (2) generate and disseminate knowledge on youth SRH needs, and best and promising practices in providing SRH education and services to youth.

The project, implemented over an 18-month period, involved the capacity building of 25 junior researchers through a training workshop, issuing of research grants, and technical assistance in proposal development and conducting of research studies. Researchers were selected from among university faculty, NGOs, and the Ministry of Health and Population. An Advisory Group (AG), composed of eight prominent researchers/ activists who are experts in the fields relevant to youth $\mathrm{SRH}$, guided the implementation of the project.

A capacity-building workshop for junior researchers in Egypt was held in March 2010 to introduce concepts of sexuality, youth $\mathrm{SRH}$ and rights, qualitative and quantitative research methods, and proposal writing. The five-day course included didactic sessions, role-play exercises, and working groups. The workshop was well received by participants who indicated that it helped them sharpen their research skills, explore new concepts, and establish networks with other researchers. It is noteworthy that some participants were uncomfortable discussing sensitive topics such as premarital sex, masturbation, and homosexuality; others showed lack of knowledge and skills in proposal writing and conducting qualitative and quantitative research. One of the positive outcomes of the workshop was the formation of an active virtual network ("Youth RH") composed of workshop participants, Advisory Group (AG) members, and Population Council staff to exchange and share news, information, documents, and materials related to youth sexual and reproductive health.

An announcement about a research competition was made at the end of the workshop and participants were invited to submit research proposals on a topic of interest related to 
youth SRH. Researchers were encouraged to work in multidisciplinary teams in order to facilitate the sharing of experiences and cross-fertilization of ideas. Seven proposals were submitted by six groups of researchers, each consisting of one to three individuals. The researchers were affiliated with four academic research institutions, two Ministry of Health and Population hospitals, and three local NGOs. Eleven workshop participants did not submit proposals because of time constraints, travel, or because supervisors did not allow them time off to conduct their own research. One researcher indicated that her supervisor did not believe youth $\mathrm{SRH}$ was a research priority at their department.

Proposals were reviewed and rated by a review committee composed of Population Council researchers along with members of the AG. Proposals had to undergo several revisions and iterations to ensure methodological and ethical soundness. All proposals that involved adolescents or exposure to more than minimal risk were reviewed and approved by the Population Council's Institutional Review Board. This step was associated with significant delays, because several researchers were not aware of the risks associated with research involving young people and/or procedures to be followed for their protection. Eventually, six studies were approved and research grants of about US $\$ 5,000$ each were issued to assist teams in the completion of their projects. Population Council staff and AG members provided technical assistance to researchers during the implementation of the studies.

\section{SIX STUDIES ON YOUTH SEXUAL AND REPRODUCTIVE HEALTH}

This section summarizes the research methodology and results of the six studies completed as part of this project. A detailed account of each study is presented in subsequent chapters. Yasmine Yousri and Heba Mamdouh of the High Institute of Public Health addressed the issue of motherdaughter communication about SRH in slum areas in Alexandria, Egypt (see Chapter 2). Although research has consistently shown that parents do not communicate with children about $\mathrm{SRH}$, the reasons they do not communicate and how children feel about this lack of communication are seldom examined. Using focus group discussions (FGDs) with mothers and adolescent daughters, Yousri and Mamdouh examined patterns of communication and barriers that interfere with adequate communication. Separate FGDs were conducted with mothers and daughters to allow each group to talk freely.

The study revealed insufficient communication between mothers and daughters on matters related to SRH. Even among mothers and daughters who regarded their relationship as "close," there were taboo topics that were never discussed, such as marriage, pregnancy, sexuality, and sexu- ally transmitted diseases. Lack of information and lack of communication skills were among the main challenges that prevented mothers from communicating with their daughters. Lack of trust was also evident among both mothers and daughters. Mothers were afraid that "too much" information might encourage their daughters to engage in inappropriate behavior, while daughters were afraid to ask questions or to reveal information to their mothers lest they get punished. On the positive side, both mothers and daughters appreciated the importance of communication with each other and were willing to talk to and listen to each other, but they did not know how to do it.

Another study that examined parent-adolescent communication was conducted by Haytham Mahmoud Hassan of Al-Azhar University (see Chapter 3) who assessed father-son communication among more than 300 male teachers, administrators, and workers in Sharkiya Governorate (northeast of Cairo). This school-based survey found a marked inconsistency between fathers' attitudes and their communication behavior. Whereas the majority of fathers believed that their adolescent sons should know about SRH issues, believed that no association existed between discussing SRH with their sons and inappropriate behavior on the part of the child, and believed that communication about SRH was not against customs or religion, less than half reported discussing such topics with their sons. Interestingly, no differences were found in communication behavior among the three occupational groups (teachers, administrators, and workers). However, fathers' knowledge of $\mathrm{SRH}$ topics, especially pubertal changes, was associated with increased communication with their adolescent sons.

Egyptian schools supposedly provide basic RH information to third-year preparatory students (ninth grade) through the science curriculum. However, anecdotal evidence indicates that this curriculum is seldom taught. Fatma El Zahraa Geel, a social scientist at Egypt's National Population Council, examined the views of students, teachers, and supervisors in regard to the teaching of this $\mathrm{RH}$ module through in-depth interviews (IDIs) with a convenience sample of these groups (see Chapter 4). Her study confirmed reports that this module is barely taught in Egyptian schools, despite students' expressed interest in information about SRH. Although teachers acknowledged the importance of teaching adolescents about $\mathrm{SRH}$, they did not feel comfortable or equipped to teach the course, especially to students of the opposite sex. Ministry of Education officials believe in the importance of educating students about $\mathrm{SRH}$, but they do not see it as a priority; others do not think school is the right venue to teach this subject to young people. Both teachers and supervisors blame conservative social norms and parents' resistance to educating their children about SRH as barriers that hinder proper teaching of the course. 
Health care providers presumably serve as credible and reliable sources of information about SRH for young people. "Youth-friendly" clinics have been established in Cairo and several other governorates, with the assistance of international organizations. Although the purpose of these clinics is to provide $\mathrm{RH}$ services and information to young people in a private and comfortable setting, service statistics from the clinics point to severe under-utilization. Hala El Damanhoury and Dalia Abdelhameed (see Chapter 5) examine attitudes and behaviors of health care providers in "youth friendly" clinics through in-depth interviews (IDIs) with service providers and "mystery clients" (MCs). The latter are male and female researchers who presented at the clinics as clients. The study findings suggest inadequate quality of care in these clinics, with deficient information offered to youth, judgmental treatment by providers, and blatant breaches of client privacy and confidentiality. Health care providers in these clinics were unaware of the SRH needs of youth and had strong biases against youth sexual behavior, unresolved moral conflicts, and ethical dilemmas toward youth sexuality. Expectedly, providers were more tolerant of male sexual activity and more willing to provide male clients than female clients with information and advice. El Damanhoury's study also revealed institutional factors, such as lack of training of service providers, lack of service-delivery guidelines, and inadequate registration and follow-up procedures, which further undermined the quality of care and contributed to under-utilization of "youth friendly" clinics.

Married adolescent girls in Egypt are particularly impacted by the unavailability of $\mathrm{RH}$ information and services, because they are often poor, uneducated, and have limited mobility and no decision-making power. Early marriage is a salient issue in rural Upper Egypt where many girls are married before the legal age of 18. Manal Darwish and colleagues at Assiut University explored the SRH experiences of married adolescent girls in three rural communities in Upper Egypt through IDIs with married adolescent girls and FGDs with their mothers/mothers-in-law (see Chapter 6). The study revealed a number of problems and risks that married adolescent girls are exposed to, including sexual dissatisfaction and sexual violence. These girls' first encounter with sex (on the wedding night) is usually traumatic, because the girls have to undergo rapid defloration by their husband (or a traditional birth attendant) to demonstrate their virginity. Before getting married, none of the girls received information from their mothers or family members on what to expect regarding sexual relations or the wedding night. Moreover, communication between these girls and their husbands was generally poor, especially on matters related to sex or achieving sexual satisfaction. Mothers/mothers-in-law did not think the problems experienced by adolescent wives were serious, however they acknowledged that some information by a reliable source, such as a female doctor, would be helpful.
Aside from sexual violence, many young women in Egypt are exposed to sexual harassment, which is becoming common, especially on the streets of large cities. Research by the Population Council (2011) has shown that half of the young women in Egypt aged 10-29 years had been sexually harassed. Mona Hassan and her colleagues conducted IDIs with 30 young men in Greater Cairo to understand their attitudes about sexual harassment and their motivations for engaging in such behavior (see Chapter 7). Their study showed a widespread belief among young men that sexual harassment was not a form of sexual abuse but a socially acceptable form of flirtation that is enjoyed by some women. Participants tend to justify sexual harassment and genderbased violence as a response to provocation by the woman, if she dresses or acts "inappropriately." Reasons that young men gave for sexually harassing women are seeking a sexual outlet, achieving sexual pleasure, and complying with peer pressure. Moreover, the study revealed highly conservative gender norms and a perception of women as irrational sexual beings whose behavior needs to be controlled by the men in their families.

\section{WHAT HAVE WE LEARNED?}

The above six studies, which delve into territories that have been rarely tackled, have shown that studying youth $\mathrm{SRH}$ is feasible, albeit difficult. Research on young people faces many challenges, including accessing participants, obtaining their informed consent (and that of their guardians), and most importantly making participants comfortable enough to talk about their sexual attitudes or behaviors. The researchers who conducted the studies used creative ways to recruit participants while soliciting the support of their guardians. For example, Yasmine Yousri and Manal Darwish and their colleagues involved the gatekeepers in their studies (e.g., mothers/mothers-in-law) by conducting FGDs with them. Involving gatekeepers helps allay their anxiety about questions to be asked of young people and provides an additional perspective on the results.

Gaining access to participants posed a challenge for some of the researchers. To overcome this barrier, several worked through local NGOs, health care facilities, friends, and acquaintances to facilitate entry into the communities. The school-based survey by Haytham Mahmoud Hassan was conducted in a convenience sample of schools, because getting permits to conduct a survey in public schools would have been extremely difficult. While these approaches limit the generalizability of results, this might be the only feasible way to study youth $\mathrm{SRH}$, given current restrictions on granting permits to researchers. 
In addition to making a contribution to the literature on youth $\mathrm{SRH}$, which is scarce in the Arab region, these studies help dispel a widely held misconception about participants' reluctance to discuss sexuality-related topics. All six studies included questions pertaining to sexuality, and two of the studies had explicit questions about participants' sexual behavior. Manal Darwish and her colleagues succeeded in getting women to share their sexual experiences and disclose sensitive aspects of their relations with their husbands. On the other hand, Mona Hassan and her team had difficulty recruiting men to talk about sexual harassment, probably because they recruited young men in public cafés without having liaisons assist in making the introduction. Young men who agreed to participate in Hassan's study, however, shared their views on sexual harassment freely and some admitted to engaging in such behavior. It should be noted that both studies used the IDI technique, which allows more time for establishment of rapport with the participant and offers some flexibility in reordering and rephrasing sensitive questions.

In terms of results, the six studies confirm reports and anecdotal evidence that youth in Egypt are eager to know more about SRH but their access to such information is extremely limited. Lack of awareness of youth SRH issues is not only prevalent among youth but is widespread among the gatekeepers (parents, health care providers, and teachers). While the gatekeepers tend to acknowledge the importance of educating youth about $\mathrm{SRH}$, they are reluctant to assume the responsibility of doing so. Parents are afraid of addressing these topics with their children, lest the children engage in inappropriate behavior. Teachers feel embarrassed to talk about $\mathrm{SRH}$ and are afraid of parents' reactions, while health care providers are willing to talk about them but only within the domain that is consistent with their own values. The culture of silence surrounding youth $\mathrm{SRH}$ is pervasive and serves as a formidable barrier against healthy transitions to adulthood for Egyptian youth.

Lack of SRH information among youth is taking its toll on young people and society at large. Young women who get married without any preparation for sexual relations experience shock at their first sexual encounter, which probably affects their sexual relations for the rest of their lives. Likewise, young men fall victim to myths and misconceptions about male and female sexuality and hence engage in violent sexual behaviors to assert their superiority over women. In this climate of conflict and lack of information and trust, young men and women are unlikely to develop positive attitudes toward their bodies and sexuality, let alone have healthy relationships based on mutual love and respect.

\section{THE WAY FORWARD}

Additional research to understand youth perspectives about $\mathrm{SRH}$ is greatly needed. As much as qualitative research provides insights into the problems affecting youth and the impact of these problems on their lives, more quantitative research is needed to understand the magnitude of these problems, their geographic and demographic distribution, and their association with other behaviors or aspects of young people's lives. Operations research is also needed to test the effectiveness of different intervention strategies to reach youth, parents, teachers, and others.

To build a cadre of researchers who are capable of conducting methodologically and ethically sound research, the capacity building of researchers in youth SRH should continue. As more researchers are "empowered" with such knowledge and skills, they can form a constituency of change agents within their institutions. They can promote greater understanding and appreciation of youth SRH research among the gatekeepers in academic institutions and security agencies. The Revolution of 25 January, led by young people, broke many social and political taboos. It is hoped that the new spirit of democracy and freedom will carry forth into the research arena and lead to more innovative studies that challenge deeply engrained taboos regarding youth $\mathrm{SRH}$. 


\section{REFERENCES}

Al-Shdayfat, N. and G. Green. 2011. "Reflections on sex research among young Bedouin in Jordan: Risks and limitations," Culture, Health and Sexuality 14(1): 101-111.

Assaad, R. and F. Roudi-Fahimi. 2007. "Youth in the Middle East and North Africa: Demographic Opportunity or Challenge?" MENA Policy Briefs. Washington DC: Population Reference Bureau.

Bruce, J. 2003. "Overview and Reflections of Child Marriage and Adolescent Policy." Washington, DC: International Center for Research on Women (ICRW).

DeJong, J. and G. El-Khoury. 2006. "Reproductive health of Arab young people," BMJ 333(7573): 849-851.

Global Forum for Health Research and World Health Organization. 2007. "Research Capacity for Mental Health in Low and Middle-Income Countries: Results of a Mapping Project." Geneva, Switzerland: Global Forum for Health Research.
Parker, R. 2009. "Sexuality, culture and society: Shifting paradigms in sexuality research," Culture, Health and Sexuality 11(3): 251-66.

Population Council. 2011. "Survey of young people in Egypt." Final Report. Cairo: Population Council.

Roudi-Fahimi, F. and S. El Feki. 2011. Facts of Life: Youth Sexuality and Reproductive Health in the Middle East and North Africa. Washington, DC: Population Reference Bureau.

United Nations Population Division. 2011. World Population Prospects: The 2010 Revision. New York: United Nations. <http://esa.un.org/wpp/>. Accessed 12 May 2012.

Wahba, M. 2011. Questions by male and female adolescents. (In Arabic.) Cairo: Egyptian Family Health Society. 


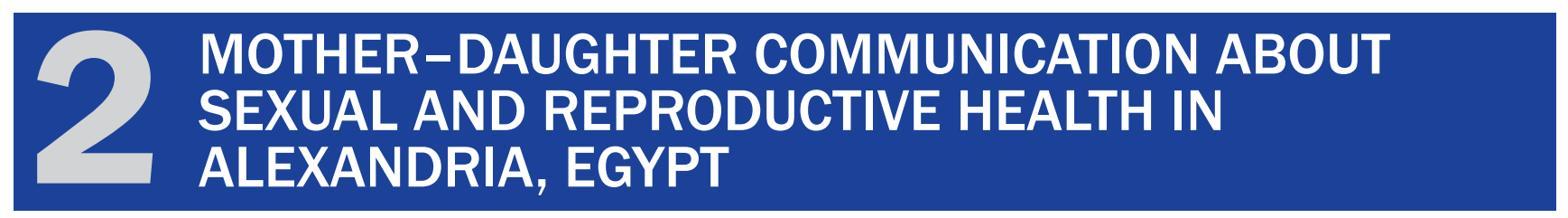

\author{
YASMINE YOUSRI ${ }^{*}$ \\ HEBA M. MAMDOUH
}

\section{SUMMARY}

Adolescents, especially girls, are often reluctant to seek information on sexual and reproductive health $(\mathrm{SRH})$ issues from adults in their family, community, or in professional settings because of associated cultural sensitivities and taboos. Hence they tend to be poorly informed about their bodies, health, sexuality, and physical well-being. Adolescents who live in slum areas are at even greater risk for health problems and risky behaviors. Although studies have reported that parents are the preferred source for SRH education for adolescents worldwide, the communication between mothers and their adolescent daughters in Egypt needs careful assessment.

The general aim of this research is to understand mother-daughter communication patterns regarding SRH in a slum area in Alexandria Governorate, and to identify key barriers to adequate communication. The target population is adolescent girls aged $13-16$ years and their mothers. Using qualitative research methods, a total of 12 focus group discussions (FGDs) were carried out, six with mothers and six with daughters. Informed consent was obtained from all participants before conducting the FGDs.
Generally, the daughters declared that they had deficient knowledge regarding many aspects of SRH. The pattern of communication between mothers and daughters was generally poor. Even mothers and daughters who considered themselves as having a close relationship and a good communication process admitted that there are still taboo topics that could never be discussed, including marriage, sexuality, sexually transmitted diseases, and pregnancy. Although girls tend to prefer their mothers to be the prime communicator, many communicate with individuals other than their mothers such as other adult family members.

Several barriers were found to hinder effective mother-daughter communication, such as cultural influences, mothers' insufficient knowledge and communication skills, and lack of trust between mother and daughter. Despite these barriers, several mothers and daughters were willing to talk to, and listen to, each other. The findings of this study suggest a need to address mother-daughter communication barriers to ensure a healthy transition to adulthood.

\section{BACKGROUND}

Adolescents undergo physical, physiological, and psychological changes that make them particularly vulnerable to health risks, especially in the area of SRH. The SRH needs, experiences, and socialization of young women are quite different from those of young men. Egyptian adolescent girls experience several problems, such as early childbearing with high rates of unintended pregnancies and unsafe abortion (Silberschmidt and Rasch 2001; Ellis et al. 2003). In addition, they suffer more sexual $\mathrm{SRH}$ risks as a result of traditional practices, such as female genital mutilation (FGM) and consanguineous marriage (Population Council 2011).
In many parts of the world, adolescents have been a neglected group largely because of cultural sensitivities and gender disparities regarding sexuality. The same is true in Egypt where adolescents may be reluctant to ask for help from adults in their families, communities, or in professional settings. Girls, in particular, are often kept from learning about SRH because of conservative cultural and religious beliefs (Cornejo et al. 2004). Young people may be at risk for SRH problems because they lack knowledge, information, and access to services and programs. Additionally, psychological and social barriers limit their autonomy and

\footnotetext{
* Yasmine Yousri is Assistant Lecturer of Maternal and Child Health, High Institute of Public Health, Alexandria University.

E-mail: yasmine.yousri@gmail.com.
} 
ability to advocate for their emergent needs (Barnett and Schueller 2000).

Although adolescents in many developing countries lack basic SRH knowledge, they rarely discuss sexual matters explicitly with their parents or other adults either because they are embarrassed or because the adults may not know much about SRH (Shaikh and Rahim 2006; Lesta, Lazarus, and Essen 2008). Also, parents may feel ill-prepared, uncomfortable, or embarrassed to talk about sex with their children. Well-meaning parents and other adults, eager to protect their children, may believe that education about SRH would encourage young people to become sexually active (Barnett and Schueller 2000). These challenges are compounded by limited resources and the fact that little is known about the needs of this age group or about what program strategies are effective, especially in developing countries (Senderowitz 2000).

Studies have reported that parents are among the most preferred sources of SRH education for adolescents worldwide (Cornejo et al. 2004; Juma, Askew, and Ferguson 2007; Nobelius et al. 2010). Enhancing the quality of communication between parents and adolescents can, in fact, help delay the onset of sex. Clarifying morals and values is an important role for parents and other adult relatives to play. Moreover, programs that involve families are often less likely to encounter political or community opposition (Sedlock 2000).

Women living in slum areas suffer not only from poor environmental conditions and lack of services, but are subject to a heavy composite burden of poverty, socioeconomic disadvantage, gender inequality, and poor health (Muhammad and Abdel-Atti 2002; Kharboush et al. 2005; Nawar et al. 2008). Thus, adolescents living in slum areas may be at even greater risk than those living in other parts of the country for health problems and risky behaviors. This highlights the urgency for understanding the informational needs of this disadvantaged group and addressing the social, cultural, and programmatic barriers that hinder communication between adolescents and parents in slum areas.

\section{STUDY OBJECTIVES}

The overall aim of this study is to understand mother-daughter communication patterns regarding $\mathrm{SRH}$ in slum areas in Alexandria Governorate and to identify barriers that interfere with adequate communication. The study was designed to answer specifically the following questions:

- What is the extent of mothers' and daughters' knowledge about SRH?

- To what extent do mothers and daughters communicate about $\mathrm{SRH}$, and what is the pattern of communication?

- What barriers prevent mothers and daughters from communicating about SRH?

\section{METHODOLOGY}

The target population included adolescent girls aged 13-16 years and their mothers living in El Amrawy (a slum area in Alexandria Governorate). This age group was chosen because this is the time when girls undergo major physical and emotional changes during which communication between mothers and daughters becomes crucial. The sample was recruited with assistance from staff of a local NGO that provides services in this area (Gam'eyt El Amrawy).

Qualitative research was chosen because of the exploratory nature of the research problem under investigation. Data collection was carried out through conducting FGDs with mothers and their adolescent daughters. A total of 12 FGDs were conducted (six with mothers and six with adolescent girls). In addition, two pilot FGDs, one for mothers and the other for daughters, were conducted. Each FGD was composed of 8-10 mothers/adolescent girls who had given consent to participate in the study. The focus groups were conducted during April and May of 2011.

Mothers and daughters had to meet certain criteria to participate. Daughters included female adolescents between the ages of 13 and 16 years who resided in El Amrawy district. This age group was chosen as opposed to a younger group because it was assumed that they were old enough to share their experiences related to knowledge and communication regarding $\mathrm{SRH}$. Mothers were biological mothers of the female adolescents and had to be residing with them.

The following topics were discussed with mothers and daughters during FGDs: knowledge of pubertal changes; topics of discussion between mothers and daughters; attitudes about discussing SRH topics; barriers that prevent motherdaughter communication; sources of information on SRH; and mothers' and daughters' informational needs.

An NGO staff member, who was also a raeda rifiya (family planning outreach worker), facilitated entry into the community, provided names of potential participants, and assisted in the recruitment of eligible participants. After explaining the study objectives and procedures, those who agreed to participate were invited to go to the NGO center at the scheduled date and time where the FGDs were held.

Informed consent of mothers and their daughters was sought before conducting the FGDs. Each mother signed both a "Participant Consent Form" and a "Parental Consent Form" (for their daughter's participation). It was stressed that one's acceptance to participate was not contingent on the other's participation. No mothers refused to allow their daughters to participate. Girls were assured that they could refuse to participate even if their mother had accepted.

The fact that mothers were participating in the study together with their daughters made obtaining parental consent 
easier. Adolescent girls gave verbal consent, indicating that they had been informed about the study and had agreed to participate. Participants were assured that participation in the study was completely voluntary and that they could stop at any time.

FGDs were held in the NGO meeting room. The initial plan was to hold mothers and daughters' FGDs simultaneously, however the NGO had a single meeting room hence this was not feasible. Mothers' FGDs were held first, because the convenient time for mothers was in the morning, whereas for daughters it was in the afternoon after school. We asked the mothers to not disclose the issues that arose during the morning discussion with their daughters.

\section{RESULTS}

\section{Participants' Socio-demographic Characteristics}

Mean age of the mothers was 40 and their mean age at marriage was 20.1 . Women had an average of 3.4 children. Table 2.1 summarizes the demographics of participating mothers. Mean age of daughters was 13.7. Almost all daughters (97 percent) were enrolled in preparatory or secondary schools, whereas only two girls (3 percent) were working for cash.

\section{Social Norms and Gender Values}

Deeply rooted cultural norms and values played a key role in shaping the content and quality of mother-daughter com-

\begin{tabular}{|lrr|}
\hline \multicolumn{3}{|c|}{$\begin{array}{l}\text { TABLE } 2.1 \\
\text { Socio-demographic characteristics } \\
\text { of participating mothers }\end{array}$} \\
\hline $\begin{array}{l}\text { Characteristic } \\
\text { Number }\end{array}$ & Percent \\
\hline Mothers' education & 20 & 30.0 \\
\hline Illiterate/read and write & 14 & 21.5 \\
\hline Primary/preparatory & 32 & 48.5 \\
Secondary or above & & \\
\hline Husbands' education & 11 & 16.7 \\
\hline Illiterate/read and write & 24 & 36.4 \\
Primary/preparatory & 31 & 47.0 \\
Secondary or above & & \\
\hline Marital status & 58 & 88.0 \\
\hline Married & 8 & 12.0 \\
Widowed & & \\
\hline Mothers' occupation & 58 & 88.0 \\
\hline Housewives & 6 & 8.0 \\
Professional jobs & 2 & 4.0 \\
Nonprofessional jobs & 66 & 100.0 \\
\hline Total & &
\end{tabular}

munication, especially on SRH issues. Although most mothers reported treating their sons and daughters equally, daughters reported that their parents still treated them differently than their brothers. Boys were punished less, were bought more clothes, received more food, were allowed more freedom, and were even given authority over their sisters.

"A boy is different from a girl; he carries the name of the family. A girl gets married and leaves the house, while the boy carries the responsibility. A woman who has not had a boy is childless."

-MOTHER, 45 YEARS, ILLITERATE

On the other hand, mothers agreed that they care and worry more about girls because they are more vulnerable and are exposed more to various risks, consequently they need more protection than boys. Protection of girls' virginity and honor is a primary concern for all mothers, thus they are keen on getting their daughters married early.

Disagreement was found between mothers' and daughters' perceptions of careers and the future. Mothers' only concern was having their daughters get married as soon as they finish secondary school. Mothers were not very keen about their daughter's career or their obtaining higher education. This was not the case with the girls, who seemed to be more educationoriented.

"We should make our education a priority. We should delay marriage until finishing higher education. Suitable age for marriage should not be before 25 years."

\section{-DAUGHTER, 14 YEARS, PREPARATORY SCHOOL}

Abstinence was emphasized by all mothers and daughters. Religious teachings, cultural values, and norms prohibit girls from having any extramarital relationships. Despite this, some mothers mentioned that premarital relationships are not uncommon in their community.

Mothers and daughters perceived sexual harassment as a major risk to which girls are exposed on the streets, on transportation, and even at schools. Some mothers and daughters reported that girls are also exposed to homosexual harassment at their schools. Mothers agreed that the community was getting more and more unsafe for their daughters. Many daughters reported that they knew girls at school who were being blackmailed by boys to have sex with them. Several girls mentioned that they had colleagues at school who were sexually active. Both mothers and daughters agreed that it is 
a girl's responsibility to avoid sexual harassment because it all depends on her behavior-the way she dresses, talks, or walks.

In general, mothers believed that girls today are different than they were when they were young. They thought that girls today have more autonomy and independence, are not forced to marry against their will, and have the right to choose whom they will marry. Almost all mothers believed that girls today are less disciplined than they were when they were their age, however two mothers mentioned that girls today were better and even more religious as evidenced by the veils they wear.

\section{KNOWLEDGE ABOUT SEXUAL AND REPRODUCTIVE HEALTH}

In general, daughters acknowledged that they had deficient knowledge regarding many aspects of $\mathrm{SRH}$, and they expressed dissatisfaction with the low level of information they had received.

"People think we know everything, but this is not true. We feel that we do not have enough information about reproductive health. Also much of the knowledge we do have is incorrect." -DAUGHTER, 14 YEARS, PREPARATORY SCHOOL

Both mothers' and daughters' knowledge about the adolescent period was not adequate regarding age of puberty, pubertal changes, and physical and emotional changes that girls go through during this period. Girls mostly acquired information from the school curriculum. A few girls described adolescence as the period where they begin to fall in love. Others mentioned it was the period where girls begin to be interested in themselves and their appearance.

Surprisingly, daughters showed better knowledge than their mothers regarding menstruation. Girls, however, did not know what menstruation was and how it was related to pregnancy and marriage. Also, some girls had misconceptions about sanitary napkins and personal hygiene during menses. Knowledge among daughters about marriage, conception, delivery, and even how to preserve virginity was poor, which was also revealed in the responses of the mothers regarding these issues.

"I know that it is harmful to use the sanitary pads; my relative got infertile after using those pads. Also we heard that they may cause ovarian cysts and can cause infertility."

-DAUGHTER, 15 YEARS, SECONDARY SCHOOL
Mothers' and daughters' knowledge about sexually transmitted infections (STIs) was also deficient, however girls had slightly less understanding of STIs and their mode of transmission. Several mothers could name two or three STIs, including AIDS, and knew the modes of transmission. The majority had misconceptions about certain STIs, such as gonorrhea, which they stated were men's diseases, while others mentioned that STIs were Western diseases not found in Egypt. Daughters could name two or three STIs at maximum, however the concept of sexual mode of transmission was not clear in their minds and some believed that these diseases could not be transmitted between a husband and wife. Some believed STIS could only be transmitted if one had a very high number (100300) of sexual partners, or if they shared the same bathroom with an infected person.

Many mothers still believe that female circumcision is important to curb sexual desire despite questioning its religious backing, benefits, and harm. Some noted, however, that sex workers in their community had probably been circumcised and that FGM could cause more harm than good. The daughters revealed a deficient level of knowledge regarding FGM, with those who had not been circumcised admitting that they did not know how it was performed or its risks or benefits.

Many mothers showed an understanding of the anatomy of the hymen and mentioned some types of it, but they did not know the difference between those types. On the other hand, the girls did not know anything about the hymen except that hymen means 'honor.'

"We heard that there are different types of hymen. There is a type called 'balata' (tile), another named 'a'enaba' (grape), and there is the one that escapes (flees). I think this name refers to the elastic hymen ... but I do not know what the other names refer to."

-MOTHER, 35 YEARS, SECONDARY-SCHOOL EDUCATED

\section{Communication about SRH}

The consensus among mothers was that their relationship with their own mothers differed significantly from that with their daughters. Unlike the distant relationship they had with their mothers that left them feeling shy and fearful, they all mentioned having closer relationships with their daughters. Owing to the poor relationship they had with their own mothers, mothers appreciated the necessity of building a closer relationship with their daughters. Many mothers and daughters shared similar stories to illustrate the strength of their relationship. 
It is noteworthy that while mothers claimed that they were trying hard to improve their relationship with their daughters, several mothers and daughters had frustrations about their communication with each other.

"My daughter does not talk with me; I do not know why. I want to talk with her, but she prefers to talk with her aunt. I also hear her talk with her friend over the phone."

-MOTHER, 36 YEARS, UNIVERSITY EDUCATED

"I speak with my mother a lot. We are close, but I wish we were closer, to speak with her about myself, for her to tell me about herself. I wish I could feel more comfortable talking with her."

-DAUGHTER, 16 YEARS, SECONDARY SCHOOL

All mothers agreed about the importance of motherdaughter communication to provide guidance to their daughters and ensure that they did not get information from unreliable sources. Almost all daughters expressed confidence in relying on their mothers to help them with their problems rather than relying on their peers. Daughters also believed that having good mother-daughter communication is crucial to gaining SRH information that is not found in books. Both mothers and daughters agreed that having good-quality mother-daughter communication is crucial for the protection of a girl from making mistakes or engaging in risky behaviors.

"A girl who does not talk with her mother or has a bad relationship with her might get into unofficial marriage (Orfi), or her friends might push her to make mistakes. I know a girl who is not close to her mother whose friend encouraged her to have a boyfriend, and he wanted to do bad things with her. When she refused, he tarnished her reputation everywhere."

-DAUGHTER, 15 YEARS, SECONDARY SCHOOL

"My mother and I, we do not talk to each other at all, and that's better. She doesn't know anything about me. We just talk once a month. She asks me whether I got my period or not, and that's it."

-DAUGHTER, 13 YEARS, OUT OF SCHOOL
Mothers did not agree on whether their daughters should be informed about some SRH topics and who should inform them. Many believed that they should discuss with their daughters SRH topics that were not taboo in order to protect them. Others wanted their daughters to be informed, but not by the mother. Some mothers preferred to withhold information about SRH from their daughters until marriage because they believed that too much information would encourage them to engage in risky behavior. For some mothers, their procommunication attitude had arisen because of the negative experience they had had when they got married and had not been adequately informed about intimacy issues.

"We wish our daughters would learn about such things so as to raise their awareness. But we cannot talk with them.... We wish that you talk with them and save us from embarrassment."

-MOTHER, 40 YEARS, PREPARATORY-SCHOOL EDUCATED

In general, communication patterns between mothers and their daughters were poor and one-sided. While mothers felt that they had good communication with their daughters, daughters mentioned that their mothers rarely communicated with them except by giving instructions and by giving warnings but without providing explanation. Some mothers believed that including religious quotes in SRH communication and advice to their daughters would make it easier and defer the girl from asking further questions, because the girl would be convinced.

"When I was about to get circumcised, I asked my mother why are you doing this? She said Prophet Muhammad did so for his daughters.... So I kept silent and obeyed her, as this must be the right thing." -DAUGHTER, 14 YEARS, PREPARATORY SCHOOL

Mothers and daughters distinguished between three types of topics: those that are explicitly discussed, those that are implicitly discussed, and those not discussed at all. The topics mothers believed could be openly and freely discussed without tension between a mother and daughter were those concerning discipline and emphasizing good behavior and societal concerns, the negative consequences of having premarital relations, and health problems or diseases in genital areas or breasts. Some mothers said that they could openly discuss love stories (if the daughter falls in love) with their daughters. The daughters, on the other hand, reported fewer topics as being appropriate to discuss. They discuss relationships only with their friends. Most feel embarrassed to open a dialogue with their mothers about love stories. 
In addition, mothers and daughters were comfortable talking with each other about menstruation and closely related topics, such as cramps and pads. This was the most frequent topic mothers discussed with their daughters. However, most daughters said that their mothers did not tell them about menstruation before they began menstruating, which resulted in feelings of shock. Mothers also did not speak with their daughters about the anatomical and physiological changes that girls experience during puberty before they started to undergo such changes.

"No one ever mentioned this to me before. My mother had never mentioned it and when I got it (period), I started screaming in the bathroom and thinking "What is this blood?" I then went home and asked my sister." -DAUGHTER, 14 YEARS, PREPARATORY SCHOOL

Interestingly, some girls prefer not to know anything about menstruation before they get their period. Some mothers agreed, saying that if her daughter knew about menstruation before she got it, this might cause her anxiety and discomfort. Most girls who did know about menstruation before they got their period reported hearing about it from their elder sisters, friends, relatives (aunts, cousins), or books they studied at school.

Mothers showed great interest in discussing some topics related to protection of girls' virginity, marriageability, and circumcision (FGM). However, these issues are neither discussed explicitly nor frequently between the girl and her mother, unless the girl is about to marry.

For protection of the girl's virginity, all mothers asked their daughters to take care during washing the genitals after urination and not to ride bicycles. The justification provided to daughters was to avoid injury to this sensitive area. They preferred not to further explain any details either because they were too embarrassed or they believed that the girl knows everything hence there is no need to go into further detail.

"I talk with my daughter about everything. I told her take care of this area (genitalia), nobody should touch it, you are an adult now, you should not raise your voice while talking, you should preserve your hymen ... it is a single use, once it is injured the girl is lost, and she will not be able to get married.... I said that to her when she first got her period."

-MOTHER, 45 YEARS, PREPARATORY-SCHOOL EDUCATED
Despite being viewed by the majority of the mothers as a favorable and important practice, mothers felt hesitant about talking openly with their daughters about FGM either because they were not totally convinced about it or because discussing issues related to sexuality is considered taboo. Although most of the interviewed girls were circumcised, most of their mothers did not discuss it with them before or after they had been circumcised. Some girls expressed that they were annoyed because they should know why they are getting circumcised and how it is to be done.

Even mothers and daughters who considered themselves as having a close relationship and good communication admitted that some topics are still taboo, such as marriage, sexuality, STIs, Urfi marriage, pregnancy, and delivery. Most mothers agreed that a girl should talk with her aunt or other trusted relative when she is about to get married.

"Other subjects (other than menstruation) she would know later. However, I should assume my role and talk with her at the wedding night. This generation already knows everything."

-MOTHER, 40 YEARS, PREPARATORY-SCHOOL EDUCATED

On the other hand, most of the girls showed eagerness about knowing how pregnancy occurs, the link between menstruation, pregnancy, and marriage, and the route of delivery. Mothers felt uncomfortable answering their daughters' questions regarding these topics. Daughters also showed dissatisfaction with the responses they got from their mothers.

"When I ask my mom how pregnancy occurs or how she delivered us, she tells me "from my mouth, I vomited you, and she laughs.'” -DAUGHTER, 14 YEARS, PREPARATORY SCHOOL

Interestingly, while daughters showed interest in SRH knowledge, they reported that they would not allow their future daughters to have such knowledge.

"I like to know more about these topics, but if I have a daughter I will not allow her to watch television or to learn about these issues. Maybe when she grows up around 20 years." -DAUGHTER, 14 YEARS, PREPARATORY SCHOOL

Mothers agreed that a mother should not initiate a dialogue on SRH topics with her daughter. However, watching a relevant television commercial, program, series, or film, or an experience of a relative or a friend, may trigger the mother to open such topics with her daughter. 
A few daughters who sought information or advice from their mothers concerning SRH issues admitted using tactics such as pretending it was a friend's or colleague's problem. This tactic allows them to first test their mothers' reactions; then, accordingly, girls would decide whether to continue asking for advice or stop.

\section{Communication Barriers}

Mothers mentioned several barriers against SRH communication with their daughters. Communication about many SRH topics is considered a cultural taboo. Most mothers reported that since they did not receive any SRH information from their own mothers, they should not discuss these issues with their daughters. In addition, many mothers felt embarrassed to discuss SRH with their daughters. A few mothers reported that their mothers (grandmothers) always advised them against talking to their daughters about such issues.

"I did not tell her about menstruation because I thought it was too early to do so. Also, her father (God bless his soul) was very strict and protective of her. He prevented me from discussing such issues with her."

-MOTHER, 45 YEARS, UNIVERSITY EDUCATED

Most mothers admitted that they were not adequately prepared to discuss SRH issues with their daughters either because they needed to learn more about how to deal with their daughters or they did not have sufficient knowledge to discuss such issues.

"We do not have enough knowledge about such things and also we do not know what to tell our daughters concerning these issues. We wish that you teach us so that we can teach our daughters and talk with them."

-MOTHER, 38 YEARS, PRIMARY-SCHOOL EDUCATED

Many mothers believe that too much SRH knowledge may encourage daughters to engage in a sexual experience or a risky sexual behavior. Others believe that their daughters have better knowledge than they do because they have access to different sources of knowledge.

"She knows everything and I know that she knows and she knows that I know, then let's remain silent and not talk to each other about it." -MOTHER, 35 YEARS, PREPARATORY-SCHOOL EDUCATED
Daughters mentioned many barriers that stand in the way of their SRH communication with their mothers. Embarrassment was the main barrier mentioned by daughters. Some girls reported feeling embarrassed to even tell their mothers or their sisters that they were menstruating, especially when they got their first period. In addition, the majority of the girls believed that their mothers felt embarrassed about discussing such topics with them or that their mothers did not have sufficient knowledge to satisfy their informational needs. Moreover, several girls feared the reaction of their mothers, believing that it would jeopardize their relationship and raise other sorts of suspicions concerning the girl's personal life. Also, indirect verbal or nonverbal messages mothers transmit to daughters make the girls recognize that these topics are taboo and stop further communication flow.

"If I talk to my mom about such issues, she remains quiet and lets me talk, then she tells my brother and he comes and yells at me and beats me."

-DAUGHTER, 15 YEARS, SECONDARY SCHOOL

\section{Sources of Information about SRH}

Television is an important source of SRH information for both mothers and daughters. Sometimes mothers allow their daughters to watch movies with mature content to avoid personally having SRH discussions with their daughters.

"The girls heard about frigidity in many films such as 'Asrar El Banat, El Na'ama w Al Tawoos and Awqat Faragh.' I swear I heard my daughter telling me "the circumcised girl is frigid." -MOTHER, 40 YEARS, PREPARATORY-SCHOOL EDUCATED

Many daughters believe that boys are privileged in having better access to SRH information and the Internet. Although many girls have Internet service, most of them cannot use it freely because of the supervision of their brother and/or mothers.

"I want to use the Internet to look for information but my brother prevents me because he says some people misuse it. When I said that he uses email, he said he was a boy but I was a girl."

-DAUGHTER, 14 YEARS, PREPARATORY SCHOOL 
An interesting source of SRH information was the gatherings organized for the bride before the wedding night. In those gatherings, one or more of the adult family members talks to the bride and teaches her about marriage and the wedding night. Many girls admit they tend to eavesdrop to hear what the bride is being told.

As for preferred sources of information, both mothers and daughters preferred to get their SRH information from a professional, like a female doctor, through counseling services at the clinic. The second preferred source was an aunt or relative. The school teacher or school-awareness sessions are the least to be considered, as girls felt their teachers did not explain SRH topics well. Use of a hotline service was not accepted either by the mothers or the daughters, who both mentioned the problem of lack of trust and the need to talk to someone face to face.

\section{Informational Needs}

Mothers and daughters acknowledged the need to fill in knowledge gaps and clear misconceptions. There was also a gap between what the daughters wanted to know and what the mothers were willing to talk about.

Disagreement was seen among girls in their attitude toward SRH knowledge. Some believed that such knowledge protects girls, whereas others believed that such knowledge increases exposure to risky behavior. Girls also have conflicts regarding their eagerness to learn about sexuality, marriage, and pregnancy and the appropriateness of having such knowledge long before marriage. They also believe that none of the adults they know would answer their questions regarding these issues.

"We want to know all that you know concerning these issues; we want to know everything about love, marriage, and pregnancy."

-DAUGHTER, 15 YEARS, SECONDARY SCHOOL

The majority of girls showed interest in learning about relationships with the other sex, and whether it is appropriate to have premarital relationships with a boy at this age. They also asked whether such relationships are condoned by Islamic teachings. Some girls showed eagerness to learn how pregnancy occurs and the relationship between menstruation, marriage, and pregnancy. Some girls experienced premenstrual symptoms, painful menstruation, and vaginal discharge, but they did not know if this was normal or not. Others wanted to know about FGM, its purpose, benefits, and dangers.

Most girls were worried about accidently losing their virginity through injury. Many asked about the anatomy of the hymen, how it can be injured, and how a girl loses her virginity. They were very anxious to know if it was easy for a girl to lose her virginity by riding a bicycle or washing her genitals vigorously.

Mothers expressed a need to learn more about topics such as masturbation and FGM. Many mothers wanted to know if FGM would cause their daughter any harm and whether the practice is with or against Islamic teachings. Also, many mothers expressed the desire to learn how to correctly communicate with their adolescent daughters.

\section{CONCLUSION}

This qualitative investigation has shed light on the nature and quality, or lack thereof, of mother-daughter communication about SRH issues. Because of cultural norms and religious perceptions in Egypt, particularly in this slum community, the most basic and fundamental of sexual information is not made known to girls when they are experiencing major bodily changes and needs with which they are completely unfamiliar. The study results confirmed the girls' need to be educated about such issues before they transition into adolescence, and that well-informed mothers could play a crucial role in ensuring a smooth and healthy development if proper communication existed between mother and daughter.

The study results highlight the need for communication interventions that would strengthen mother-daughter communication. These interventions would include training of mothers and daughters on communication skills using different approaches, providing mothers and daughters with accurate information on various SRH issues, and improving communication patterns through addressing the different mother-daughter communication barriers. Interventions for improving the mother-daughter communication patterns should take into account social, cultural, and religious values, designing and implementing an educational package on SRH for both mothers and daughters.

Mass media should encourage mother-daughter communication. Religious institutions (mosques and churches) should address misconceptions about FGM and should highlight the value of knowledge and dispel myths about withholding information from adolescents.

Communication outlets and channels should be developed to provide organized services to both mothers and daughters as needed. Community agencies such as NGOs and educational institutions should collaborate to offer discussion groups for mothers and their adolescent daughters to facilitate dialogue about SRH issues. SRH interventions targeting the families should be offered at the primary health care service. Booklets that contain basic information for mothers should be developed to assist mothers in communicating with their 
daughters. Premarital counseling services should educate prospective husbands and wives about SRH and the value of communication with their children.

Needless to say, interventions to address mother-daughter communication barriers might be challenged by the cultural taboo of sexually related topics. Therefore, changing these concepts and this excessive need to shelter girls on a nationwide scale while engaging mass media and religious institutions is as important as educating and training mothers and daughters about the importance of understanding their bodies and the SRH risks to which they may be exposed.

\section{REFERENCES}

Barnett B. and J. Schueller. 2000. Meeting the Needs of Young Clients: A Guide to Providing Reproductive Health Services to Adolescents. North Carolina: Family Health International.

Cornejo, M., R. Silva, and C. Andina. 2004. "Culturally Appropriate Information, Education and Communication Strategies for Improving Adolescent Reproductive Health in Cusco, Peru." Washington, DC: Population Council, USAID.

Ellis, Bruce J., John E. Bates, Kenneth A. Dodge, David M. Ferqusson, L. John Horwood, Gregory S. Petit, and Lianne Woodward. 2003. "Does father absence place daughters at special risk for early sexual activity and teenage pregnancy?" Child Development 74(3): 801-821.

Juma, Milka, lan Askew, and Alan Ferguson. 2007. "Situation Analysis of the Sexual and Reproductive Health and HIV Risks and Prevention Needs of Older Orphaned and Vulnerable Children in Nyanza Province, Kenya." Kenya: Population Council.

Kharboush, I.F., A.A. Youssef, M.M. Makhlouf, A.A. Zaghloul, A.A. El-Hamid, and A.G. El Masry. 2005. "Women health in poor urban settings in Alexandria," Journal of the Egyptian Public Health Association 80(1-2): 321-348.

Lesta, Stalo, Jeffrey V. Lazarus, and Birgitta Essen. 2008. "Young Cypriots on sex education: Sources and adequacy of information received on sexuality issues," Sex Education: Sexuality, Society and Learning 8(2): 237-246.
Muhammad, M.A. and M. Abdel-Atti. 2002. "Assessment of environmental and health status of two squatter areas in West Alexandria," Bulletin of the High Institute of Public Health 32(3): 541-552.

Nawar, L., H. El Kotkat, N. El Helw, H. Abo El Azm, and N. Abdel Fattah. 2008. "Informal settlements in governorates of Arab Republic of Egypt: An analytical study.” (Arabic edition.) Available at <http://www.idsc.gov.eg/Publications>.

Nobelius, Ann-Maree, B. Kalina, R. Pool, J. Whitworth, J. Chesters, and R. Power. 2010. "Sexual and reproductive health information sources preferred by out-of-school adolescents in rural southwest Uganda," Sex Education: Sexuality, Society and Learning 10(1): 91-107.

Population Council. 2011. Survey of Young People in Egypt. Final Report. Cairo: Population Council.

Sedlock, Laura. January 2000. "Reaching the youngest adolescents with reproductive health programs," In Focus. <http:// www.pathfinder.org/publications-tools/publication-series/.

Senderowitz, Judith. 2000. "A review of program approaches to adolescent reproductive health." USAID and Population Technical Assistance Project. <http://pdf.usaid.gov/pdf_docs/ PNACK597.pdf>.

Shaikh, Babar T. and Syed T. Rahim. 2006. "Assessing knowledge, exploring needs: A reproductive health survey of adolescents and young adults in Pakistan," European Journal of Contraception \& Reproductive Health Care 11(2): 132-137.

Silberschmidt, M. and V. Rasch. 2001. "Adolescent girls, illegal abortions and 'sugar-daddies' in Dar es Salaam: Vulnerable victims and active social agents," Social Science and Medicine 52(12): 1815-1826. 


\title{
A SURVEY OF FATHER-SON COMMUNICATION CONCERNING SEXUAL AND REPRODUCTIVE HEALTH IN SHARKIYA, EGYPT
}

\author{
HAYTHAM MAHMOUD HASSAN
}

\section{SUMMARY}

Good quality parent-adolescent communication regarding sexual and reproductive health (SRH) is essential for reducing risky sexual behavior among adolescents. Such communication is limited in Egypt, however, especially among adolescent boys. The quality of SRH communication between parents and adolescent males needs to be assessed in order to design interventions that will enhance such communication and increase young people's knowledge of SRH.

The overall objective of this study is to examine fatherson communication practices regarding $\mathrm{SRH}$. Data was collected through a school-based survey of 358 fathers who have adolescent sons between the ages of 13 and 16 . These fathers were recruited from schools in Al-Hosainia district in Sharkiya Governorate and included teachers, administrators, and workers. Participation in the research study was completely voluntary and informed consent was obtained from all subjects.

The study revealed that 60 percent of fathers have never communicated with their sons about $\mathrm{SRH}$, although 84 percent of fathers believed that their adolescent sons should know about these issues. Moreover, about two-thirds of fathers ( 65 percent) believed that no association exists between communication with their sons on reproductive health $(\mathrm{RH})$ issues and inappropriate behavior of the child. Also, about 68 percent of fathers believed that communication with their sons is not against customs or religion.

The study showed that fathers' communication with their sons about SRH issues was associated with their knowledge of different aspects of SRH as well as their religious attitudes. Study results indicate the need for health education programs for fathers to increase their knowledge about SRH issues and to strengthen their communication skills.

\section{BACKGROUND}

Adolescents are a demographic and economic force as well as the cohort that will determine the future of the country. Many behavioral patterns acquired during adolescence last a lifetime and have the potential to influence the health and well-being of the future generation. Youth SRH is the result of interactions of biological (i.e., pubertal changes), emotional, reproductive and sexual health, lifestyle, and social influences. Youth SRH is also affected, to a great extent, by several factors including family, school, community, and government policies. Young people suffer from marginalization and neglect as far as their sexuality and sexual health is concerned. They have unmet needs with regard to basic SRH information and services because of a lack of available specialized services, a lack of timely and optimal information, and social restrictions and taboos on the discussion of sexuality. Even married young people suffer from lack of access to important information (El-Kak 2003).

Family is one of the earliest and most important influences on adolescent sexual development and socialization. Theory suggests that the quantity and quality of parental communication plays a crucial role in influencing children's behavior and hence reducing adolescent risky sexual behavior through fostering responsible sexual decision-making (Wilson and Donenberg 2004). Moreover, research studies confirm that parent-teen communication that is open, receptive, and comfortable is associated with less sexual experience and less risky sexual behavior among adolescents (Mueller and Powers 1990; Miller et al. 1998; Whitaker et al. 1999).

\footnotetext{
*Haytham Mahmoud Hassan is Lecturer of Public Health at Al-Azhar University. E-mail: haytham1972@yahoo.com.
} 
Young people aged 10-29 represent 42 percent of Egypt's total population. Despite the paucity of research on adolescence in Egypt, evidence suggests that parent-adolescent communication about SRH is limited. A national survey conducted by the Population Council showed that parents do not discuss reproductive health and sexuality issues with their children. The situation is particularly serious for adolescent boys, of whom only 7 percent indicated that they received information on pubertal changes from their parents compared with 44 percent of girls (Population Council 2011). Many factors may be responsible for the lack of communication between parents and their children, such as parent/adolescent shyness, lack of information among parents, feelings of inadequacy and fear of raising children's curiosity to try risky behaviors. The above-mentioned survey of young people in Egypt did not examine the dynamics of communication between parents and children, nor did it identify underlying reasons for low levels of communication. Such information is crucial for overcoming barriers to communication and eventually raising adolescents' awareness about SRH.

\section{STUDY OBJECTIVES}

This study's primary objective is to explore the issue of fatherson communication concerning SRH by examining: (1) fathers' communication practices in relation to SRH; (2) fathers' attitudes regarding communicating about $\mathrm{SRH}$ with their adolescent sons; (3) socio-demographic, knowledge, and attitudinal factors associated with increased father-son communication about SRH.

\section{METHODOLOGY}

The study utilized a quantitative cross-sectional data collection approach, using a school-based survey of a convenience sample of fathers of adolescent boys working in the schools. Initially, the study was designed as a home-based survey, however because of difficulties in finding fathers at home, despite repeated callback visits, the study was switched to a school-based survey. The target population was fathers of adolescent boys aged 13-16 years. The researcher recruited 358 fathers between March and June 2011. The study was conducted in one city and two main villages in Al-Hosainia district in Sharkiya Governorate. Al-Hosainia district was selected using random sampling from a list of all the districts of Sharkiya Governorate. Since Hosainia district has only one city (Al-Hosainia city) and about six main villages, Al-Hosainia city was selected while two villages were selected using simple random sampling. The school sample was selected based on the presence of a contact person who could facilitate access to fathers employed in those schools.

\section{Data Collection Procedures}

In each school, the researcher met with the supervisor to explain the aim and procedure of the study and the long-term benefits expected. After getting their verbal consent, any father of any category in the school (teacher, administrator, or worker) having 13-16-year-old adolescent boys was approached for the study. The aim of the study was explained and subsequently informed consent was obtained. Three male data collectors participated in data collection. They received one week of training by the principal investigator on administration of the questionnaire and obtaining informed consent.

A pilot study was conducted on a sample of ten fathers to test the questionnaire and data- collection procedures. Pilot testing was conducted in a village that was not selected for the study. Based on the results of the pilot study, the questionnaire was slightly modified and the study was switched to a school-based survey.

The main challenge faced was difficulty in finding fathers at home, hence the study was switched to a school-based survey. Furthermore, many fathers did not understand the meaning of adolescent $\mathrm{RH}$, while others thought it only meant sexual health. There was also a lack of interest and cooperation among some community leaders in the study villages.

\section{RESULTS}

\section{Socio-demographic Characteristics of Fathers}

The total number of interviewed fathers was 358. Table 3.1 shows that most of the fathers participating in the study were 40-49 years of age (66.2 percent), university educated (51.7 percent), and working as teachers (56.4 percent), while more than 90 percent had three children or more (mean was 3.8). Almost half of the wives of the studied fathers were secondary school-educated (47.8 percent) and about two-thirds were not working for cash (64.2 percent).

\section{Fathers' Knowledge and Attitudes about Se- lected Sexual and Reproductive Health Topics}

When asked about their knowledge of $\mathrm{RH}$ issues, 48 percent of fathers believed that they were very knowledgeable and 43 percent somewhat knowledgeable, whereas 6 percent believed they were not knowledgeable. Fathers were asked questions to verify their knowledge of pubertal changes. Hoarseness of voice was the most frequently mentioned physiological change associated with puberty ( 93.3 percent), followed by psychological changes (88.0 percent), increased body hair (87.7 percent), and muscle growth (76.5 percent). Interestingly, pubertal changes related to sex (e.g., wet dreams, interest in the opposite sex, and growth of genital organs) were mentioned by less than 50 percent of fathers (Figure 3.1).

Television is the main source of information for fathers on matters related to sexual and reproductive health as mentioned by 62 percent of the study participants, followed by friends (41 percent), books (38 percent), magazines (36 


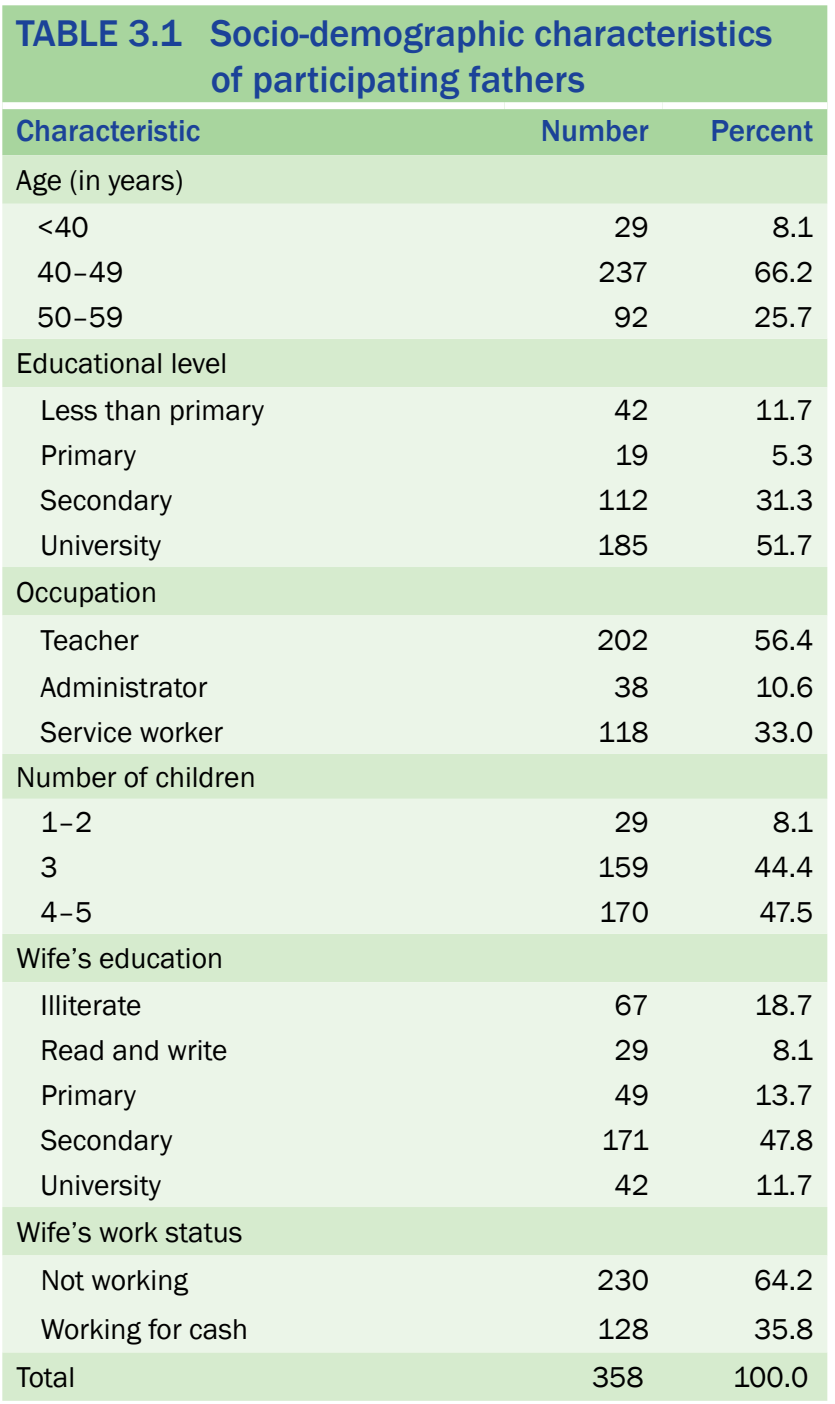

percent), and family (17 percent). Health providers were mentioned by only 8 percent of fathers.

Fathers were asked to list all the family planning (FP) methods they knew. IUDs and oral pills were mentioned by more than 97 percent, whereas condoms were unlikely to be mentioned ( 1 percent). The majority of the fathers reported ever use of FP (95.8 percent).

Fathers' attitudes about female genital mutilation (FGM) were mostly positive, with about two-thirds (63 percent) considering it a good practice (Figure 3.2). Slightly less than two-thirds had already had their daughters circumcised (61 percent) and about one-third planned to have their daughters circumcised later. Only 5 percent of fathers indicated that they did not plan to circumcise their daughters. Fathers mainly supported FGM for religious reasons (33 percent) or to decrease their daughters' sexual desire (26 percent).

When asked which sexually transmitted infections (STIs) they knew of, almost all interviewed fathers (99 percent) mentioned AIDS; a much smaller portion mentioned gonorrhea (40 percent) and syphilis (31 percent). All interviewed fathers who had heard of AIDS mentioned sexual relations as a main route of transmission followed by blood transfusion (71 percent) and contaminated needles (54 percent), while maternal-fetal transmission was the least mentioned mode (7 percent). Slightly less than half the fathers stated correctly three modes of AIDS transmission (45 percent), whereas only 5 percent knew all four modes.

\section{Father-Son Communication Practices}

Most fathers (60 percent) never communicated with their sons about SRH-related issues. Among those who did, the most fre-

\section{FIGURE 3.1 Fathers' knowledge of physical and emotional changes associated with puberty}

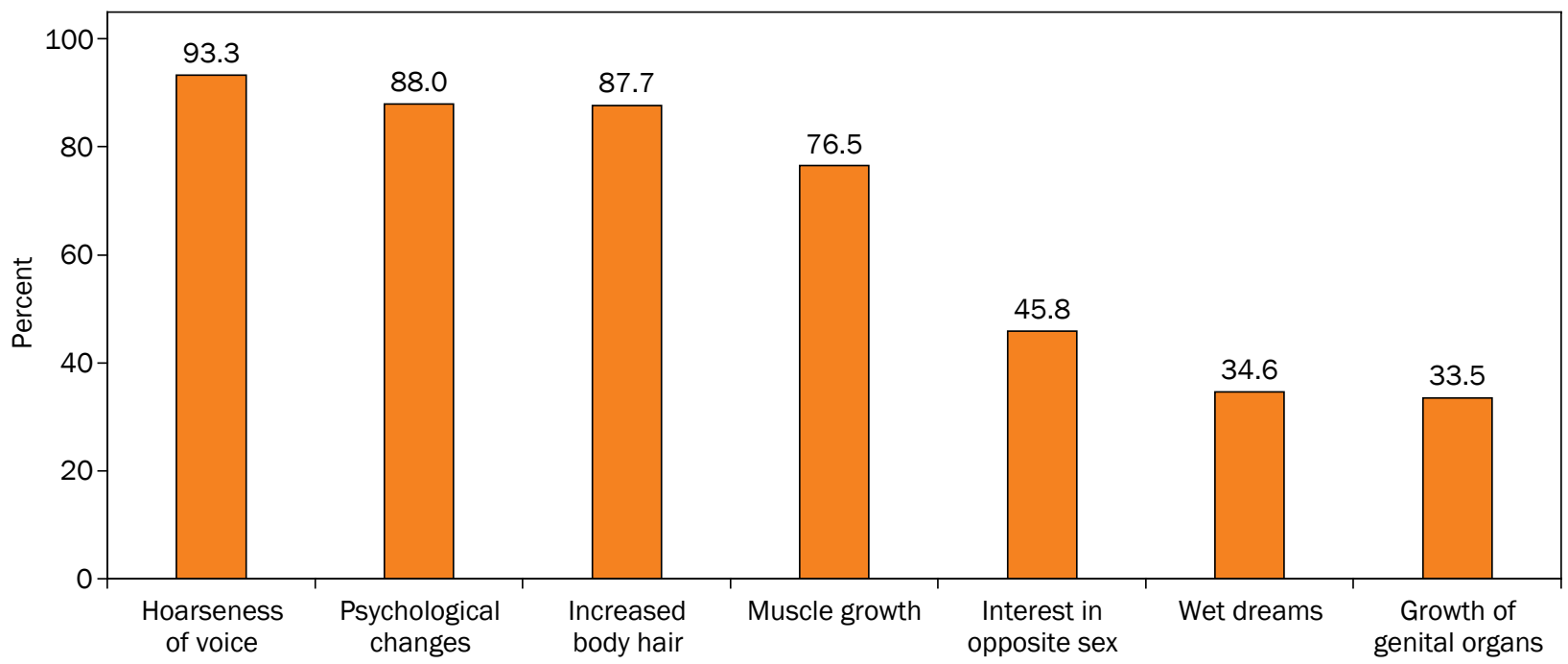


FIGURE 3.2 Fathers' attitudes about female genital mutilation

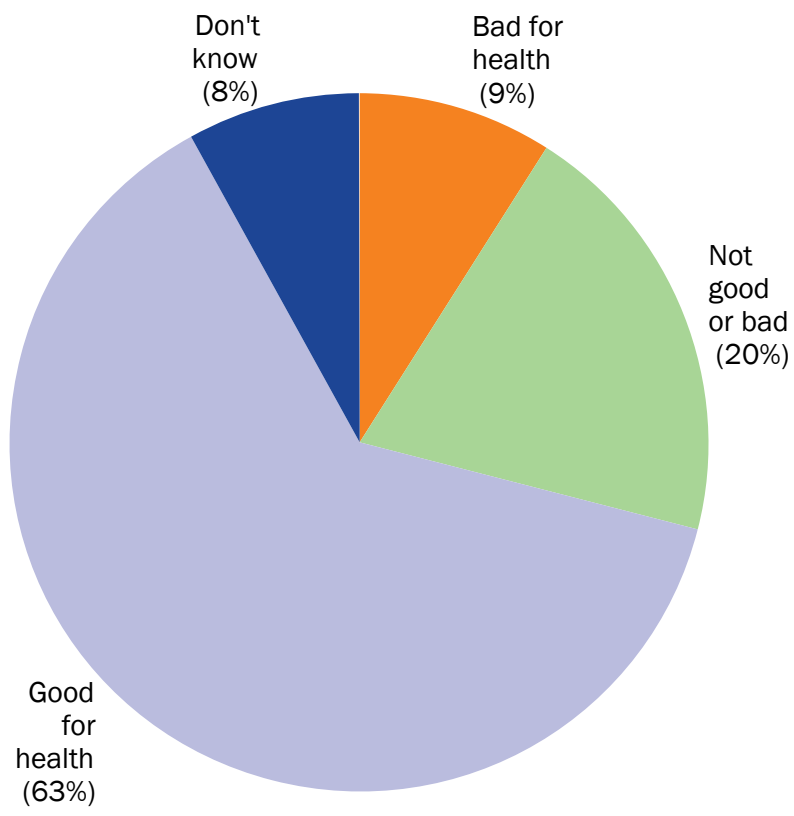

quently mentioned topics were puberty, STIS/AIDS, and masturbation (37 percent, 18 percent, and 17 percent, respectively).

The most commonly mentioned reasons for not communicating were: fathers' belief that it was inappropriate to talk with sons about these issues (37 percent), belief that sons were too young to discuss such issues (28 percent), or belief that sons had other sources of information (13 percent). Among fathers who communicated with their sons about $\mathrm{SRH}$, communication started at 13 years of age or older in 52 percent of cases, and between 10 and 12 years of age in 44 percent of cases. Two out of three fathers communicated with their sons every 1-2 months, and the remainder communicated less often. Communication was initiated by fathers in about 80 percent of cases.

Regarding the experience of communication between fathers and their sons, one-third of fathers believed that their sons were very embarrassed during the communication versus two-thirds who believed they were slightly embarrassed or not embarrassed. As for the fathers, 75 percent felt comfortable during the communication, and 25 percent felt slightly or very embarrassed.

Among fathers who communicated with their sons, 64 percent believed their sons were very interested in this communication. Regarding usefulness, 87 percent of fathers believed that communication with their sons was very useful, 10 percent believed that it was somewhat useful, and only 3 percent believed it was not useful.
It is noteworthy that slightly more than half of fathers believed they had sufficient information to discuss SRH issues with their sons (53 percent), whereas the others believed their information was "to some extent sufficient" or not sufficient.

\section{Fathers' Attitudes toward Sons' Knowledge of Reproductive Health}

The majority of fathers (84 percent) believed their sons should know about SRH in order to protect them from "illegitimate practices" or to increase their knowledge. On the other hand, the reasons given by those who believed that their adolescents should not know about SRH issues were to prevent them from illegitimate practices ( 64 percent), the belief that it was inappropriate (27 percent), or the belief that it was not needed (9 percent).

When specifically asked if talking with their sons would lead to inappropriate behavior, most fathers (64 percent) believed no association existed. Moreover, more than two-thirds of fathers disagreed that communication with their sons about $\mathrm{SRH}$ issues was against customs or religion.

\section{Factors Associated with Father-Son Communication}

Bivariate analysis showed the following variables to be associated with father-son communication about SRH: father's knowledge of five or more pubertal changes, belief that discussion of SRH is not haram (religiously prohibited), belief that discussion would not lead to inappropriate behavior, belief that a son should know about SRH, and father's perceived sufficiency of knowledge. However, after controlling for potential confounders, the following variables were found to be the strongest predictors of father-son communication about SRH (Table 3.2): occupation of service worker as opposed to teacher or administrative worker ( $p=0.006$ ), belief that father-son communication about SRH would not lead to inappropriate behavior ( $p<0.001$ ), father's perception that he has sufficient knowledge about SRH $(p=0.03)$ and belief that adolescents should know about SRH $(p=0.02)$.

\section{CONCLUSION}

This study reflects the current status of father-son communication in one community in Egypt regarding SRH issues and emphasizes how culture and religion are strongly intertwined with health communication in these communities. Although results showed that fathers acknowledge the need for more $\mathrm{SRH}$ information as well as transparent communication about these issues with each other, barriers still prevent this from effectively taking place.

The study showed a lack of knowledge about SRH among fathers. It also showed positive associations between per- 


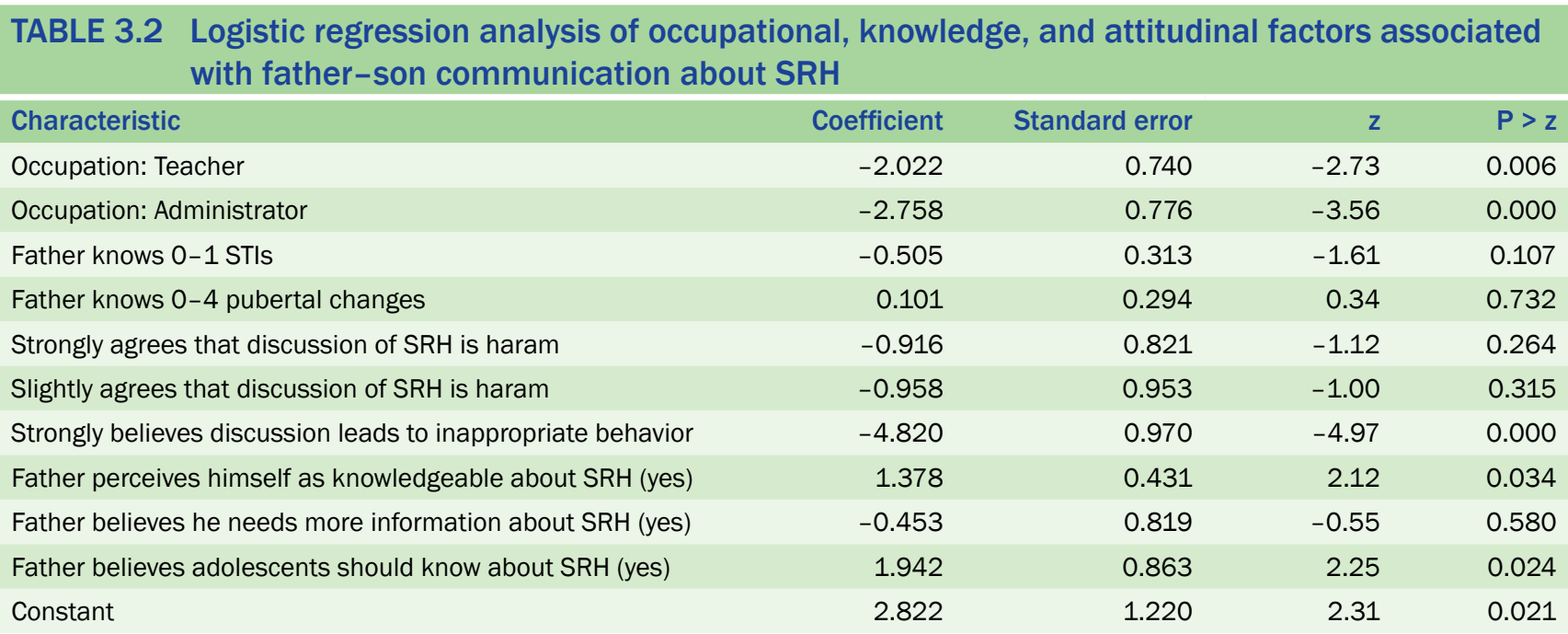

ceived knowledge and communication. This speaks to the importance of increasing both fathers' knowledge about SRH and their communication skills as part of any intervention to establish effective communication channels between fathers and sons about $\mathrm{SRH}$ issues.

Strangely, the results showed that teachers and administrators were less likely to communicate with their sons about $\mathrm{SRH}$ issues than service workers, which raises concern about their role not only as fathers but as educators, and calls for immediate action. Also shown was that fathers who had more favorable attitudes toward SRH, namely those who were less likely to perceive that it would promote inappropriate behavior, were more likely to communicate with their sons.

Based on this study, it is important to take into consideration that stakeholders not only need to demonstrate the importance of SRH education, particularly during the vulnerable stage of adolescence, but to address the prevalent embarrassment and "tabooing" caused by such topics that hinder effective communication.

Accordingly, health education programs for fathers are needed to increase knowledge about SRH issues and emphasize the importance of early communication in prevention of many health problems affecting their sons. These programs should highlight the issues of adolescent $\mathrm{RH}$ in its broader context and not just the sexual elements. Extra emphasis should be placed on educating and training teachers and social workers at the Ministry of Education so they can better communicate with their own offspring as well as their students.

Mass media is a preferred source of information for most participants. Thus introducing SRH information for parents and adolescents in mass media programs (especially television) is essential. In addition, strategies should be developed for having referral institutions/centers provide fathers with face-to-face information about SRH for adolescents (e.g., mosques and churches, youth centers, and NGOs), which could provide information and address fathers' questions and concerns. Misconceptions about adolescent knowledge regarding $\mathrm{SRH}$ and inappropriate behavior, and $\mathrm{SRH}$ being against religious beliefs need to be rectified. As such, engaging religious leaders in spreading awareness about the importance of SRH education and emphasizing that it does not conflict with religious beliefs would be crucial. Finally, operations research is needed to test the efficacy of various interventions for reaching fathers with youth SRH information.

\section{REFERENCES}

El-Kak, F. 2003. "Background Paper on Reproductive and Sexual Health in the Eastern Mediterranean Region." Beirut: World Health Organization, Regional Office for the Eastern Mediterranean.

Miller, B., M. Norton, X. Fan, and C. Christopherson. 1998. "Pubertal development, parental communication, and sexual values in relation to adolescent sexual behaviors," Journal of Early Adolescence 18(1): 27-52.

Mueller, K.E. and Powers W.G. 1990. "Parent-child sexual discussion: Perceived communicator style and subsequent behaviour," Adolescence 25(98): 469-482.

Population Council. 2011. "Survey of young people in Egypt." Final Report. Cairo: Population Council.

Whitaker, D. et al. 1999. “Teenage partners' communication about sexual risk and condom use: The importance of parentteenager discussions," Family Planning Perspectives 31(3): 117-121.

Wilson, H. and G. Donenberg. 2004. "Quality of parent communication about sex and its relationship to risky sexual behavior among youth in psychiatric care: A pilot study," Journal of Child Psychology and Psychiatry 45(2): 387-395. 


\title{
SEXUAL AND REPRODUCTIVE HEALTH EDUCATION IN EGYPTIAN SCHOOLS: THE IDEAL AND THE REALITY
}

\author{
FATMA EL ZAHRAA GEEL *
}

\section{SUMMARY}

In Egypt, lack of knowledge among adolescents regarding sexual and reproductive health ( $\mathrm{SRH}$ ) is a growing concern. To manage the health challenges and needs of this age group, the implementation of effective school-based SRH education is essential. Although SRH education curriculums are currently available in Egyptian public schools, the quality of teaching is questionable. The primary objectives of this research study are to assess the quality of SRH education in Egyptian public schools, investigate the needs and expectations of students, and identify the main impediments to providing adequate SRH information in school.

The above objectives were achieved through the use of qualitative research methods. In-depth interviews (IDIs) were conducted with 20 tenth-grade students (12 male, 8 female) enrolled in secondary governmental schools. IDIs were also conducted with ten science teachers in intermediate schools, and four Ministry of Education (MOE) officials/ supervisors.
Study findings indicated that most students (male and female) found the $\mathrm{RH}$ information provided in school to be deficient. Discussions are often not sufficient because of the embarrassment that both teachers and students feel during the sessions. However, it was clear that students, teachers, and supervisors are concerned about $\mathrm{RH}$ and agree that teaching $\mathrm{RH}$ in schools is important. The biggest obstacles for teaching and discussing $\mathrm{RH}$ issues are community norms and teachers' inability to provide simple and accurate information.

Suggestions from students, teachers, and supervisors for overcoming some of the obstacles are: (1) segregating male and female students during SRH sessions and having lessons taught by same-gender teachers; (2) having RH specialists conduct seminars in schools for students as well as teachers; (3) increasing parents' awareness of the importance of discussing these issues with their children; (4) building teachers' capacity by providing training courses in $\mathrm{RH}$; and (5) encouraging mass media to play a role in increasing community awareness about youth RH issues.

\section{BACKGROUND}

The fact that Egypt's adolescent population is large and rapidly growing has created challenges for meeting this age group's reproductive health needs. Challenges include the paucity of research and data on adolescents, insufficient attention to enormous gender disparities, lack of information and services available to adolescents (married or unmarried), weak or nonexistent policies directly addressing adolescent youth $\mathrm{RH}$, and weak programs even where national policies exist (Hardee, Pine, and Wasson 2003; Roudi, Ashford, and Khalil 2008).

The subject of adolescent and youth SRH education is still controversial in many societies. Parents, religious and com- munity leaders, policymakers, service providers, and young people themselves often have strong opinions about the subject. Many individuals oppose programs that teach or discuss adolescent $\mathrm{RH}$ issues because they believe they are taboo topics or too embarrassing to discuss publicly (Beamish 2003). According to the Survey of Young People in Egypt (Population Council 2011), more than 73 percent of young people never discussed pubertal changes with their families.

SRH encompasses sexual development, reproductive health, interpersonal relationships, affection, intimacy, body image, and gender roles. School-based SRH education is one of the most important ways to help young people improve their current and future reproductive health. SRH health education addresses the

*Fatma El Zahraa Geel is Planning and Coordination Specialist, National Population Council. E-mail: fatmageel@hotmail.com. 
biological, sociocultural, psychological, and spiritual dimensions of sexuality. Countries in many parts of the world have organized SRH education programs of one type or another. The success of these programs depends on the extent to which the programs meet the informational needs of adolescents.

Research has consistently shown that adolescents need a source of accurate information about SRH. The majority of young people in Egypt are enrolled in school; thus, it would be unfortunate to miss the opportunity of providing accurate $\mathrm{SRH}$ information in schools. SRH education curriculums are available in Egyptian schools, mainly through science courses for students in intermediate schools (ninth grade), however little is known about the quality of teaching of those curriculums or about students' reactions to the course. In fact, some anecdotes suggest that the sections on SRH are often skipped because teachers are unprepared or too embarrassed to teach the information.

\section{STUDY OBJECTIVES}

This study's aim was to assess the quality of SRH education taught in public schools in Egypt. Specific objectives included: (1) examining students' experiences with the SRH curriculum and the extent to which it meets their needs and expectations; (2) examining teachers' experience with teaching the $\mathrm{SRH}$ curriculum; and (3) identifying barriers that interfere with teaching SRH in Egyptian schools.

\section{METHODOLOGY}

\section{Study Design}

The study used qualitative research methods, namely IDIs with students, teachers, and MOE supervisors/managers. Qualitative data was collected by conducting IDIs $(n=20)$ with tenthgrade students (who had supposedly completed the science course in ninth grade) and with science teachers who taught the $\mathrm{RH}$ course to ninth-grade students $(n=10)$. Additionally, IDIs were conducted with MOE managers and supervisors ( $n$ $=4$ ). IDIs with students, teachers, and MOE managers were tape-recorded and transcribed.

\section{Study Population}

The sample of students was drawn from nine governmental secondary schools: five in Cairo, three in Gharbia, and one in Giza. The target group was adolescent boys and girls in tenth grade. This is a convenience sample of schools where students and parents agreed to participate in the study.

The sample of ten teachers (four female and six male) was drawn from four intermediate governmental schools in Cairo. Four supervisors and managers (one female and three male) were selected from one directorate in Cairo.

\section{Data Collection}

Data collection was conducted by three researchers who were chosen for their experience in qualitative data collection. Researchers received training by the principal investigator for two days before and after conducting the pilot study. Pilot testing of the interview guide was conducted with two students, and accordingly some questions and expressions were changed, such as "sexual education" to "reproductive health education."

Recruitment of students began when the researcher obtained permission from one of the parents. The researcher relied on personal relationships to recruit the sample of students because of the difficulty of communicating with NGOs following the (Revolution of January 25th). The researcher contacted the parents (either through a personal visit or by phone) to ask if the student could participate. Once interest in the study was secured, the interviewer met with both the student and one of the parents to obtain informed consent. After the researcher had the approval of both parent and student, they agreed on a time and place for the interview. Interviews were mostly conducted during nonschool hours at the student's home, or at a sporting club, youth center, or school (only in Gharbia).

For teachers, the researcher obtained the permission of the headmaster first, and then science teachers were approached for informed consent. All IDIs with teachers were conducted at their schools. IDIs were conducted with all the supervisors and managers at their Directorate in Cairo, after obtaining informed consent.

\section{Challenges in Data Collection}

The initial plan was to meet four MOE senior officials, but this was not possible after the instability that followed the Revolution of January 25th. In addition, the study initially planned to organize IDIs through NGOs, but this was difficult because of the legal problems some NGOs faced, hence the principal investigator relied on personal contacts to recruit the student sample. Difficulties also arose in discussing sensitive topics with young people aged 14-19, especially female students, and getting approval from parents to conduct IDIs with their sons/daughters.

\section{RESULTS}

\section{Students' Knowledge about Pubertal Changes}

The findings suggest that students' knowledge is lacking, scattered, and vague, and that they need more information about RH. Most female students who participated in the IDIs stated they had information about the expected physiological changes of adolescence before their occurrence, even though 
in some cases this knowledge was limited. In comparison, male participants had less information about these changes. It is noteworthy that parents did not discuss these changes with their children before they occurred.

"No one talked to me at all because most families consider this topic taboo and they are embarrassed."

-FEMALE STUDENT, GIZA

"Yes, changes start at age 11 or 12 for both males and females and they are concentrated in muscle growth, voice changes, and body growth for boys."

-MALE STUDENT, CO-ED SCHOOL

It was evident that girls who knew about pubertal changes experienced less fear or concern about them, reflecting the positive impact that such knowledge has on girls. While the majority of female students referred to their mothers as a main source of information followed by their friends and some relatives, female students in rural areas considered peers, teachers, relatives, and books as the main source of information. For male students in both urban and rural areas, the main source of information was peers followed by the Internet and books.

"My mother talked a lot with me before puberty so I was not surprised, and when I had my menstruation I was not shocked or had any fears because my mother had told me."

-FEMALE STUDENT, CO-ED SCHOOL

When asked about their preferred source of information, females and males mentioned different sources. While female students preferred to talk with their mothers, boys preferred peers, teachers, fathers, and books, as well as the Internet. Some participants, particularly males, stressed their preference for younger teachers and they neglected to mention the family as a source.

"It is possible to talk with my friends and mom, of course, as well as school friends where we attended a seminar on that topic before in our school."

-FEMALE STUDENT, CO-ED SCHOOL
"From my teacher or the Internet, although I don't trust information from the Internet because it has a lot of bad information that could harm me."

-MALE STUDENT, ALL-MALE SCHOOL

\section{Students' Experience with the School Reproductive Health Curriculum}

All students indicated that what was covered in class by ninthgrade teachers was inadequate and unclear. They indicated that the information was limited to a description of both the male and female reproductive system, because that was what would be covered on the exam. Students stressed this point, because other $\mathrm{RH}$ issues were not addressed elsewhere in the curriculum.

Students believed that, generally, teachers felt embarrassed and did not have the ability to talk in front of them. Some students said they felt embarrassed, especially when the school was co-ed. Other students mentioned that they did not feel embarrassed because Islam teaches that there should be no embarrassment in seeking knowledge.

The subject of religion provides a great opportunity for discussions on sexuality and reproductive health, because it is accepted by many and deals with specific RH topics such cleanliness, purification for prayer through washing after having wet dreams, and so forth.

"The teacher explained it on the last days of school while most students were absent, and it was in an embarrassed and hurried manner." -MALE STUDENT, ALL-MALE SCHOOL

The students were asked about their satisfaction with the type and amount of SRH information provided. Nearly all participants could not specify whether they had received adequate information, but male and female students agreed that RH information at school was limited.

"I don't have the full picture, so I cannot say if my information is enough or not." -FEMALE STUDENT, CO-ED SCHOOL

Female students found it difficult to provide suggestions on what topics could be added to the science curriculum, because they were unaware of all the RH information they should know. A few participants were more specific and mentioned 
the reproductive system, how to keep healthy, and sexually transmitted diseases as important topics they wanted to learn more about. The same held true for the male students who were also unaware of the information they needed, although some pointed to the overall lack of $\mathrm{RH}$ information in general. Moreover, the majority of students reported that they were unable to determine the extent of the teachers' knowledge on $\mathrm{RH}$ topics because of the minimal discussions they had with teachers on the topic.

“Everything related to sex, we don't have enough information. My teachers were embarrassed, explained very little, only stuff related to the exam. This is not a main course, just one chapter within the course."

-MALE STUDENT, BOYS' SCHOOL

"I can't tell to what extent the teacher has enough information until I ask and get feedback, which does not happen due to lack of opportunity for discussions. Anyhow, I knew whatever I wanted from private lessons as the teacher separated boys from girls and discussed the issues with each group freely."

-MALE STUDENT, CO-ED SCHOOL

\section{Teachers' Perspective about RH Curriculum}

The teachers were asked the same question about the adequacy of information provided to students and to what extent it was suitable for their needs. Most teachers agreed that what they taught was insufficient.

"It is not adequate because I should be teaching STIs like syphilis and gonorrhea, and that they are transmitted through wrong practices." -MALE TEACHER, BOYS' SCHOOL

"Female circumcision is not found in the curriculum and we try to teach this information ourselves." -MALE TEACHER, BOYS' SCHOOL

All teachers stressed the importance of providing SRH information to male and female adolescents, especially those who are in eighth grade (i.e., before starting the pubertal stage). The majority of teachers realized the importance of their role in increasing students' awareness about RH. They feared students would go to unreliable sources, and considered themselves the "best" source for such information, mentioning the absence of the parents' role and their lack of knowledge about $\mathrm{RH}$ issues.

The majority of teachers indicated that they did not receive any official training in teaching $\mathrm{SRH}$. Rather, they relied on their personal experiences, the Internet, books, and friends in the health profession for their SRH information. This fact was also acknowledged by MOE officials during IDIs.

Many teachers explained that the situation is embarrassing, especially when teaching students of the opposite sex. In addition, teachers mentioned the pressure from parents who are opposed to the teaching of this material to their children. Some parents even ask their daughters to be absent on the day of the SRH lesson. As a result, some male teachers refer female students to female colleagues to explain to them in more detail and respond to their questions. The situation is not the same with female teachers who indicated that they feel comfortable teaching boys and girls.

"I can teach the session easily because they are females, but male teachers sometimes feel embarrassed and ask us to teach instead of them."

-FEMALE TEACHER, GIRLS' SCHOOL

On MOE policies regarding RH education, most teachers mentioned that at no time was an anti-RH education policy adopted by the MOE. It was the parents, as stated by teachers, who often refused to have this topic taught to their children.

"The RH sessions have been conducted for $\mathbf{2 0}$ years, which proves the support of MOE."

-FEMALE TEACHER, BOYS' SCHOOL

\section{Supervisors' Perspectives on RH Curriculum}

Directors and supervisors agreed about the importance of providing adolescents with $\mathrm{RH}$ information, believing it would have a positive effect on their well-being. However, supervisors felt the content of SRH information was inadequate, especially for this critical age group. They suggested the addition of subjects related to STIs, early marriage, pregnancy, and female circumcision. Most supervisors indicated that schools should not be the only source for such information; they suggested involving the family, mass media, the community, organizations, and youth clubs. 
"Family should be the first source of information, followed by religious organizations, youth clubs, and all other organizations, which should work together."

-MOE OFFICIAL

"Yes, it is so important to provide RH information to adolescents, and I wish they would teach these topics to students in primary schools."

-DIRECTOR AND HEAD SUPERVISOR

Despite the perceived efforts of the MOE as stated by teachers, the majority of supervisors pointed to the sensitivity of $\mathrm{RH}$ as a topic and explained why the MOE is always avoiding discussion of it. Repeatedly, directors indicated the low priority of this topic, hence their monitoring visits did not focus on teaching methods but rather on the curriculum as a whole.

"To be honest, issues concerning the RH curriculum are sensitive topics and we do not discuss them much in the MOE. Recently, we have been thinking to include such topics just for general information, not for exams."

-MOE OFFICIAL

"All the topics are important, so we follow the teaching process during all sessions not only this specific session."

\section{-FEMALE SUPERVISOR OF BIOLOGY}

Supervisors attributed teachers' embarrassment when teaching SRH topics to the social context that discourages all discussions pertaining to these issues. Teachers' lack of proper preparation on this topic also contributes to the problem.

"MOE should provide training courses in SRH to teachers to build their capacity and enable them to provide accurate information in a simple way. Moreover, mothers should also help teachers by discussing such issues with their children at home, so they (children) do not get surprised when the topic is explained to them.

-FEMALE SENIOR INSTRUCTOR OF BIOLOGY

\section{Suggestions of Students and Teachers}

Participants offered several suggestions to address the current status of SRH education in schools. Many agreed on separating male and female students in co-ed schools during $\mathrm{RH}$ - related discussions. Other propositions included providing a separate, more detailed RH curriculum to span more than one school year. Further, some suggested increasing parents' awareness about SRH issues to enhance communication and for better acceptance of SRH education at school. Others proposed that the MOE be responsible for providing formal training to the teachers in $\mathrm{RH}$ education and perhaps hire younger teachers who can communicate more effectively with students of that age group. Votes were split over adopting a religious approach versus a purely scientific approach of teaching, while some believed that there was value in integrating $\mathrm{RH}$ education in both science and religious curriculums. Finally, to encompass more relevant issues and be culturally sensitive, a director of chemistry in one school suggested changing the name to "Family Health" instead of "Reproductive Health."

To better support the teaching of SRH, teachers indicated that they need some tools, such as displays (posters, electronic projectors) and books as well as training courses to raise their knowledge level and improve their teaching capabilities. Providing for these needs would be an effective step forward.

"Books in our library are important; boys can borrow and discuss the issues during the class."

-FEMALE TEACHER, BOYS' SCHOOL

"We should separate boys and girls, and also it should be male teacher for male students and female teacher for female students. Teachers should be qualified enough to provide us with all the information we need within the context of religion."

-MALE TEACHER, CO-ED SCHOOL

"I suggest integrating $\mathrm{RH}$ within the religious studies curriculum to make it more acceptable. Moreover, don't remove it from the science curriculum, because it is relevant to science since it involves the reproductive system and health." -MALE CHEMISTRY SUPERVISOR 


\section{CONCLUSION}

The findings make it clear that the current study of SRH education in schools is very limited and requires development and formal integration within the curriculum. In Egypt, many cultural norms and religious perceptions appear to hinder the acceptance of such a relatively novel and progressive approach, therefore thoughts of teaching SRH through religion, science, or both were also entertained. Based on this unarguable need, education authorities should take necessary measures to meet this demand.

Findings from the study would support the recommendation that the Ministry of Education build teachers' capacity in teaching $\mathrm{RH}$ and provide job aids such as books and flip charts. Drawing on the experience of other countries would be useful, such as Tunisia, which was the first country in the Arab region to introduce SRH in school curriculums, Iran with its mandatory family population and family planning classes, and Turkey with its exceptional coverage of SRH in school curriculums and teachers willing to engage in discussions on this topic. Lebanon is in the process of revamping its national curriculum on $\mathrm{SRH}$, and early evaluation and adaptation of these efforts in Egypt may be of relevance. In addition, extracurricular activities within schools conducted by specialists in this area should include seminars and conferences that are attended by both teachers and students.
Reviewing $\mathrm{RH}$ topics in religion classes is also recommended, because it will provide more opportunities for discussion about these issues within the context of religion and thus may be more acceptable from the point of view of the community. Other recommendations include raising community awareness about the importance of discussing SRH with adolescents to help prevent risky behavior. This can be achieved by involving mass media, religious institutions, and youth clubs.

\section{REFERENCES}

Beamish, Julia. 2003. "Adolescent Reproductive Health in Egypt: Status, Issues, Policies, and Programs.” Washington, DC: Futures Group International, POLICY Project.

Hardee, K., P. Pine, and L. Wasson. 2003. "Adolescent and Youth Reproductive Health in the Asia and Near East Region: Status, Issues, Policies, and Programs." Washington, DC: Futures Group International, POLICY Project.

Population Council. 2011. "Survey of young people in Egypt." Final Report. Cairo: Population Council. 


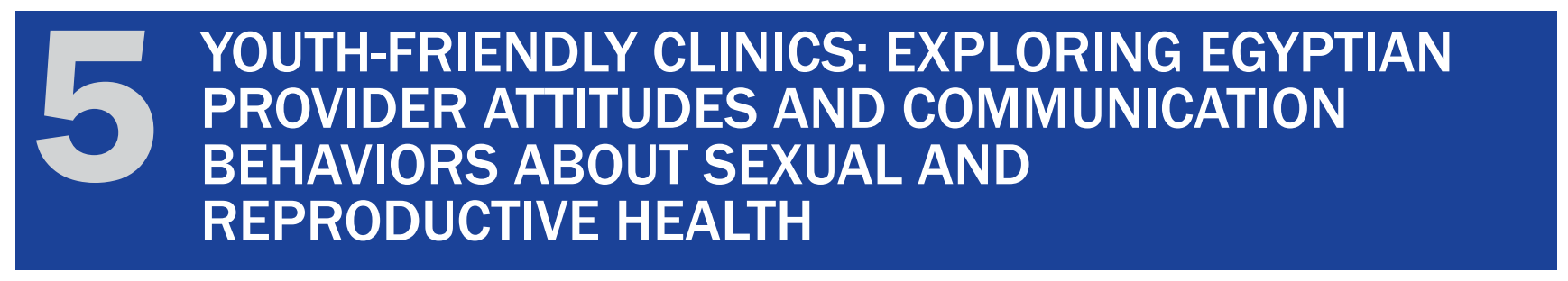

\author{
HALA EL DAMANHOURY \\ DALIA ABDELHAMEED
}

\section{SUMMARY}

Despite recent efforts to address gaps in adolescent sexual and reproductive health (SRH) services in Egypt through the introduction of Youth Friendly Clinics (YFCs), information and services are still reported to be inadequate. Enough evidence exists to show that services provided by YFCs are underutilized by youth. This underutilization may be related to sociocultural factors, such as social stigma associated with the use of YFCs, or poor client-provider interaction in those clinics.

The primary objective of this study is to explore provider factors that contribute to low utilization of YFCs in Egypt. Qualitative research methods were used and data was collected through 20 in-depth interviews (IDIs) with service providers working in 10 YFCs affiliated with the Ministry of Health and Population (MOHP) or NGOs. In addition, debriefing meetings were made with two young mystery clients (MCs), one male and one female, who provided reports of interpersonal communication between MCs and providers in the above 10 clinics through 16 visits.

The aim of the IDIs was to collect data on service providers' perceptions of different youth reproductive health $(\mathrm{RH})$ issues as well as their role in providing services to youth. MCs reported on the following areas: provider's time with client, rapport building by provider, privacy for counseling during visit, and ease and content of communication between client and provider. Informed consent was obtained from all participating YFC providers and from the MCs. In addition, approval was obtained from the regional supervisors overseeing the ten sampled YFCs.

Findings revealed overall disapproval of adolescent sexual activity among health care providers and unwillingness to provide services to unmarried women. Providers had unresolved moral doubts, negative attitudes, and ethical dilemmas toward the sensitive SRH issues of youth. Especially with an absence of guidelines and protocols explaining how to contend with such cases, it is left to the provider's conscience.

This study identified several institutional factors, including lack of provider training and service delivery guidelines, as well as negative provider attitudes that pose a significant barrier to clinic utilization. Providers asked for ongoing education and wanted policymakers to support youth-friendly services. The findings reflect an urgent need for a comprehensive policy to improve quality of services in YFCs.

\section{BACKGROUND}

The sociocultural context in which adolescents in Egypt find themselves has changed considerably in the past few decades. Adolescents are experiencing social turmoil resulting from conflicting social values between their beliefs and those of the more conservative majority of society. This social clash creates an environment that leaves youth vulnerable to risks associated with maladaptive behavior, like drug use, unsafe sex, and HIV/AIDS and other STIs. While many downplay premarital relations in the Middle East and North Africa (MENA) region, preliminary studies have shown that young people do have sexual relations before marriage. Such uninformed sexual activity often places youth at risk for STIs, unintended pregnancies, and unsafe abortions (DeJong et al. 2007).

Adolescent sexuality is a highly charged moral issue in Egypt. SRH issues are of great concern but they are surrounded by formidable social restrictions. Adolescent RH was placed on the international agenda for the first time at the 1994 International Conference on Population and Development. A number of momentous international declarations clearly

*Hala El-Damanhoury is an OB/GYN Specialist at El-Khazindar hospital in Cairo. E-mail: haladamanhoury@yahoo.com. 
outlined the need and the right of youth to have services that are appropriate for their developmental stage. Both the UN Convention on the Rights of the Child and the UNHCR Committee on Economic, Social and Cultural Rights (2003) identified countries' responsibilities to their adolescent populations and the right of adolescents to have access to sexual education, primary healthcare, and family planning (FP) services, and confidential services that respect adolescent privacy (UNHCR 2003). Despite global agreements, RH services remain grossly inadequate. Adolescent $\mathrm{SRH}$ needs are still neglected in many countries (UNFPA 2003). Young people's access to $\mathrm{SRH}$ information and services is limited. Information is often limited because of a belief that talking openly about sexual health might encourage unmarried youth to have premarital sex (DeJong et al. 2007).

In 2003, the United Nations Population Fund (UNFPA) and the Egyptian Family Planning Association (EFPA) initiated a project to meet adolescent $\mathrm{RH}$ needs in Egypt. The aim of this project was to build the capacities of clinics to deal with adolescent-specific SRH issues (Family Health International 2009). Additional YFCs were established in Egypt between 2004 and 2008 to meet youth $\mathrm{RH}$ needs. Today, there are approximately 30 clinics in Cairo and Upper and Lower Egypt. The clinics are open six days a week from 9 a.m. to 2 p.m., and some are also open for two to three hours in the evenings. Each clinic is staffed by a doctor and a nurse who have supposedly been trained in providing youth SRH services. YFCs provide the following services at subsidized prices: (1) premarital counseling/examination; (2) counseling, examination, and treatment/referral for STIs; (3) counseling, examination, and treatment of pubertal disorders; (4) counseling and provision of contraceptive methods for married youth; (5) antenatal and postnatal care, and counseling; and (6) lab services.

According to MOHP policies, YFC providers can only provide information and counseling and are not allowed to give physical examinations to unmarried youth. Cases that need medical treatment would be referred to an andrologist or an obstetrician/gynecologist.

Despite the demand for youth SRH services, YFCs are underutilized. Several factors have been found responsible for low utilization of services, including ineffective advertising, fear of stigma, and lack of female physicians in some clinics (Family Health International 2009).

Little is known about the attitudes and behaviors of staff who work in YFCs. Previous assessment studies conducted in Egypt have concentrated on the logistics of the clinics and assessment of youth needs, but did not investigate providers' attitudes or communication behaviors. Doctors and nurses are the core health care providers of adolescent SRH services. Confidentiality as well as health providers' attitudes are two important issues affecting whether or not young people use health facilities (Jones and Boonstra 2004). The interaction between personal and professional beliefs may be an issue in some cases, because providers are part of society and they may carry the same social values. Negative provider attitudes (e.g., toward sensitive issues such as premarital sex, teenage pregnancy, or STIs) may discourage young people from using YFCs.

\section{STUDY OBJECTIVES}

The overall study goal was to explore factors that contribute to low utilization of YFCs in Egypt, and to investigate the extent to which providers' attitudes can influence utilization of the clinics. More specifically the study examined: (1) communication behavior of providers in YFCs in relation to sensitive SRH issues; (2) providers' attitudes toward providing SRH services to youth; and (3) personal and institutional factors that may interfere with provision of adequate SRH services to youth.

\section{METHODOLOGY}

The study population is composed of physicians and nurses who work in YFCs. The two main types of YFCs in Egypt are affiliated with either NGOs or MOHP. We included providers in both types of clinics because those in NGOs are exposed to different training and work more closely with the community, hence their attitudes and communication behavior may be different than those in MOHP facilities. The study was conducted in ten YFCs in Greater Cairo, the Delta region, and the Suez Canal region. The above clinics included six NGOs and four MOHP clinics, and are located in urban and peri-urban areas except for one facility that is located in a rural area. The study used qualitative research methods, namely IDIs with service providers and debriefing meetings with mystery clients (MCs). Two MCs (one male and one female) were sent to the above clinics where they posed as clients.

Approval to conduct the study was obtained from senior officials in the Teaching Hospitals Organization (THO) and Egyptian Family Planning Association (EFPA) and Cairo Family Planning Association (CFPA). The above officials and providers were told that the research would involve interviewing providers and some of their clients to learn about the quality of services provided to youth.

\section{In-Depth Interviews}

Twenty IDIs were carried out with providers who worked in the above clinics after obtaining their informed consent. Each IDI lasted for 30-45 minutes and was tape-recorded to ensure complete capturing of information. Both the available physician and nurse (or social worker if the nurse was unavailable) in charge of providing the youth services on the day of the visit to the clinic were interviewed. 
Procedures to ensure confidentiality of information were maintained. The following topics were discussed in IDIs: (1) background characteristics; (2) previous training and experiences; (3) attitudes toward providing SRH services to youth and job satisfaction; (4) utilization of youth services at the clinic; and (5) perceived barriers to utilization of services by youth.

\section{Mystery Clients}

Two MCs, one male and one female, were recruited for this study. MCs, as opposed to regular clients, were used as a result of low client flow. Also, MCs had specific case scenarios, which may not be frequently encountered among regular clients. A participant was eligible to serve as a mystery client if $\mathrm{s} /$ he expressed interest in the study and if $\mathrm{s} /$ he demonstrated the ability to articulate the health problem assigned to them. Once they had expressed interest, their informed consent was obtained. MCs received two days of training on how to present the health problem to the provider, what areas of provider behavior to report on, and how to handle tough questions by providers or requests for physical exams or lab tests. They were provided with information on the locations and services of the ten selected YFCs. Caution was taken to ensure that the MC did not receive any lab tests or physical examinations during this study. To investigate differences in providers' attitudes toward male and female clients, MCs were assigned to clinics that accepted both males and females, however it was later found that some of these clinics received male clients only. Thus, the male MC made a total of nine visits, and the female $\mathrm{MC}$ made seven visits.

The following are the scenarios that were presented by the MCs:

Case 1: A 25-year-old male seeking advice for protection against STIs. In the discussion with the health provider, he reveals that he has had sex with several women in the last six months.

Case 2: A 24-year-old officially engaged ${ }^{1}$ girl (whose marriage has been registered but has not been officially consummated) complaining of missed period and positive pregnancy test. She is afraid of revealing this pregnancy to her parents for fear of punishment.

MCs were tasked with reporting on the following: (1) ease of locating YFCs; (2) time spent with each provider; (3) provider's overall attitude; (4) privacy during visit; (5) ease of communication between client and provider; (6) provider's

\footnotetext{
${ }^{1}$ The initial scenario was to present the case of an unmarried girl. However, it was later changed to "officially" married for fear of strong negative reactions against the girl by service providers.
}

reaction to the presented problem; (7) information and advice given to client; and (8) client satisfaction.

\section{Data Collection}

Twelve providers agreed to the interview being tape-recorded. The other eight refused, so for those interviews it took a longer time to document what was said. Data was transcribed on the day of the interview. Following fieldwork and review of the transcribed data, a preliminary qualitative analysis was conducted by the principal investigator with the help of a data management consultant.

\section{Challenges in Data Collection}

The initial study design included interviewing both the physician and nurse in each clinic, but it was discovered that social workers or peers also provided youth services. Two social workers in two clinics were interviewed because no nurses were available. Due to irregular attendance by some of the providers, MCs had to go to the same clinic several times. Also, recruiting MCs, especially the female client, was very difficult. One $\mathrm{MC}$ refused to continue with the study after feeling unwelcome by the nurse in one of the clinics. In light of the findings that services were not equally available to male and female clients, the study design was changed, and thus not all clinics received our male and female MCs.

\section{RESULTS}

As seen in Table 5.1, 20 providers (10 physicians, 8 nurses, and 2 social workers) were included in the study. The major-

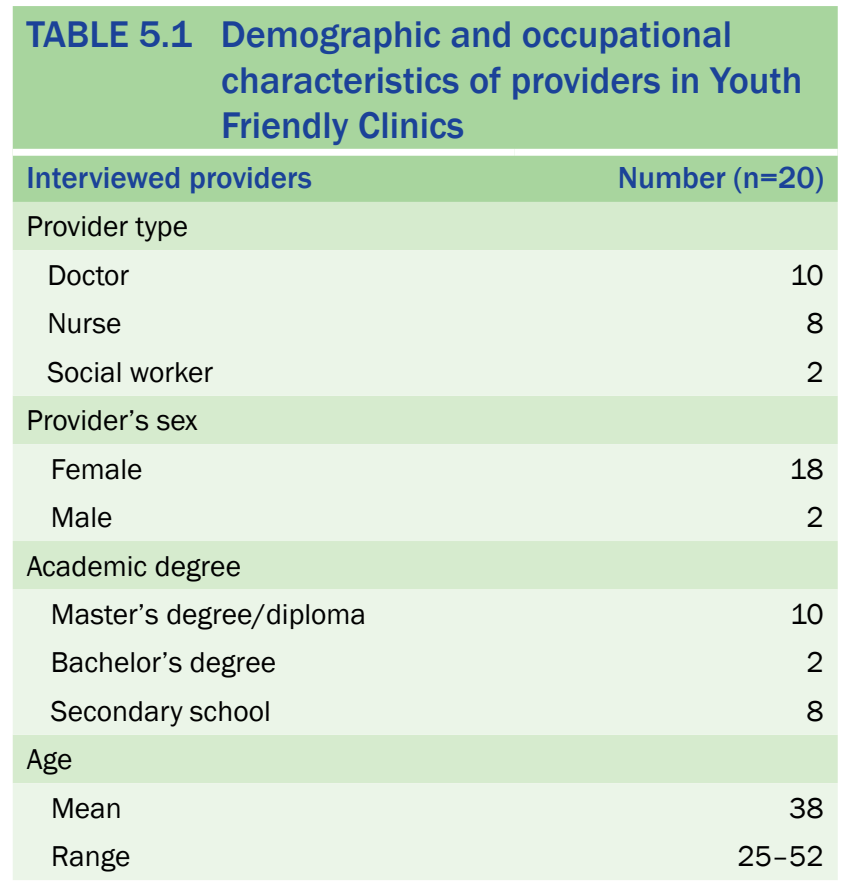


ity were female. The mean age of providers was 38 years. Most providers, especially those in the NGO clinics, had been working at the YFCs since their establishment about six years ago. Most had a bachelor's degree or diploma in Obstetrics/ Gynecology, while only one physician had a diploma in Public Health. The two male providers were andrologists and one of them had a master's degree. Some of the providers had been working in the same institution as Family Planning or primary health care physicians before joining the YFCs; others were working temporarily at YFCs while their primary affiliation is with MOHP.

\section{The Setting of YFCS}

Governmental YFCs are part of teaching hospitals; the general idea was to add YFCs to FP clinics for females and andrology clinics for males. In some hospitals, separate places existed for youth consultations, premarital testing, and counseling. Some hospitals provide services to girls only and others to both sexes on separate days.

The main service of the governmental clinics is premarital counseling and examination, as well as RH services (e.g. family planning) for married women. Providers whose primary affiliation was the Obstetrics/Gynecology department inside the same hospital tend to perceive their role with youth (if any) as counselors only.

Providers in NGO clinics included in the present study had been appointed about 20 years ago as FP service providers, then were transferred six years ago to work as youth friendly providers. Peer educators were added to lead youth education activities and to refer youth to doctors, if necessary. The number of peers working in the NGO clinics is decreasing because of lack of financial compensation.

The main function of the NGO clinic is to provide FP services. The youth clinic section is a separate room that includes a library with health books and leaflets and two computers with Internet facilities. Young people come to the library to find information by reading books and browsing the Internet. Two clinics provide video seminars where young people can get exposed to certain $\mathrm{RH}$ issues through films.

Some clinics are well connected with the community; they engage youth from the community in workshops and seminars about different health issues including $\mathrm{RH}$, and encourage them to come to the clinic to discuss health concerns with their peers and the doctor.

All MOHP facilities are located inside teaching hospitals, hence they use the hospital lab which is relatively well equipped. The labs at the NGO clinics, on the other hand, have different capacities, if any. Two clinics provide HIV/AIDS and STIs tests. Clinics that do not have HIV/AIDS testing refer cases wishing to do the tests anonymously to another clinic.
"When we first started the clinic, we had a lab technician, but the lab was closed after two years due to lack of funds and too few cases needing lab works."

-YFC NURSE, DELTA REGION

Most facilities supposedly offer services daily to females and males, except on Fridays. Some are open for two shifts, one in the morning and the other in the evening. Others specify three days for males and three days for females. Some NGO clinics in Cairo work as youth-only facilities one or two days a week. However, these schedules are not well advertised.

\section{Clinic Readiness to Provide Youth Friendly Services}

The ease in locating the clinic is an indicator of clinic accessibility and the availability of the services and also indicates the level of promotion/advertising within the hospitals or the local community. MCs were able to locate the NGO clinics more easily, because they are not part of a large hospital; rather they are separate clinics or small youth centers. However, both male and female MCs had difficulty locating YFCs that were located in hospitals, because there were no signs and in some instances staff members at the hospital were not aware of the presence of such clinics.

"I asked about the YFC in a hospital. The security guard said we don't have a YFC. I went inside the building and asked about the YFC. A nurse said, 'You may go to the andrology clinic,' and there they said they only provide premarital counseling services and, 'You can ask in the FP clinic.' When I went there, they said the service is no longer available as the YFC has been closed." -FEMALE MC

Registration services were lacking in the clinics. The majority of providers said they only had forms for married women seeking FP or for those coming for premarital counseling. In some clinics, the client's name, age, and complaint were registered, whereas opening a new file for the client was done in only three out of ten clinics. Also, it was unclear who was in charge of registration, as the person who first met the clients varied according to the setup of each clinic and the availability of staff.

Waiting time from the time the client first arrived at the facility until $\mathrm{s}$ /he saw a provider ranged from ten minutes to more than two hours. The long waiting time was mainly a result of clinics overcrowded with FP clients or the absence of the provider. 
"I had to sit in the waiting room with many women who were there for family planning services. I was so embarrassed, since all the women kept looking at me wondering why I was here."

-MALE MC IN YFC

In about 30 percent of MC's visits, they could not meet the provider on the first visit and had to return to the clinic. Two clinics had been permanently closed, while others were temporarily closed during working hours. In five clinics, the doctor was not available on that day, and in three other clinics all staff had gone for the day.

"The nurse said the doctor was on leave and that I should come back after one week. When I went back, the only physician available was a male doctor who only examined male clients. I came back again two days later and the doctor wasn't there for the third time."

-FEMALE MC

In both types of clinics, providers received many training courses. However, the majority of these courses did not cover youth SRH nor did they build the capacity of YFC providers. Rather, training was focused on other RH services in the clinics (e.g., early detection of female genital cancers, premarital counseling, and insertion of subdermal implants). All physicians confirmed that they received training in youth counseling. In NGO clinics, physicians and nurses said they were trained in communication with young people, and some had recently received premarital-counseling training.

Providers stated that there were no written guidelines; rather they recognized some cases because of their long work experience. A nurse in a YFC clinic outside Cairo mentioned that such protocols would facilitate their work. Physicians acknowledged the absence of guidelines for cases of sexual violence or adolescent pregnancy, nevertheless the doctor tries to help (on the personal level as much as possible). Rape victims are immediately referred to forensics; emergency contraceptive pills are prescribed to prevent pregnancy. In the cases of secret marriages, the doctor advised the client to disclose the marital status to the family in case of pregnancy.

Follow-up procedures were not clear. The majority of the providers reported that most youth do not come back after they get treatment or advice. Out of 20 providers, 16 considered the rate of follow-up to be lower than what it should be. Others saw no need for follow-up because most young people come to ask questions for reassurance and not for treatment.
Interestingly, one nurse in a YFC indicated that the absence of follow-up was a sign of good service.

"Not coming back is an indicator of clinic success in meeting the youth needs, as the clinic is perfect and introduces curable treatment so youth don't come back."

-NURSE IN YFC

Referral was considered by providers to be easily available in MOHP clinics because they are located inside teaching hospitals, with well-equipped labs and other facilities. NGO clinics refer clients to nearby hospitals. The main reasons for referral are: lab tests for genital tract infection and STIs, male clients when andrologist is not available in the clinic, and female clients when an obstetrics/gynecology doctor is not available. Overall, there are no clear referral guidelines and no feedback mechanisms between the referral sites and service delivery points.

\section{Providers' Perceived Roles and Attitudes}

In general, NGO providers had closer links with the community, partly because of the location of the clinics. Providers described their roles as advocates and instructors, rather than reproductive health care providers to youth. Their opinions about youth clients were positive and encouraging. Many providers added that they encourage youth to come to learn how to protect themselves against different risks and discussed with them their beliefs, misconceptions, and concerns. However, when they were confronted with an actual SRH problem, as in the case of MCs, the majority of providers refused to provide services or help.

Most providers believed that providing FP services to youth would promote promiscuous behavior or would send conflicting messages. One physician in a clinic outside Cairo mentioned that FP services should be available to married couples only.

"Girls come with their mothers for virginity check. In this case, I don't say anything (if the girl is not a virgin), because the girl knows what she had done but is playing dumb, and telling her mom is not going to change her behavior." -PHYSICIAN, YFC IN CAIRO

A few physicians showed a different attitude when asked their opinion regarding delivering SRH services to young people. They agreed that they might give unmarried youth information on contraception if asked. 
"If an unmarried girl asked me for contraception to prevent an unwanted pregnancy, I would talk seriously with her, trying to solve the problem and introduce help, because if I didn't help her, we would face a major sin which is termination of pregnancy."

-PROVIDER IN YFC, CAIRO

The majority of providers stated that youth need SRH services, at least for pubertal changes. They need counseling and reassurance because of lack of information and prevalence of misconceptions. Providers stated that youth need information about personal hygiene, smoking, drugs, and early marriage. Some girls come for premarital counseling and ask about the details of sexual relations and how they can prepare themselves before the wedding.

Findings revealed a general disapproval among providers toward adolescent premarital sexual relations and abortion. However, providers were more accepting of male than female sexual activity and were willing to help the former. Very few providers believed in the importance of providing services to youth regardless of their marital status.

"Youth have a right to get reproductive health services like the condom. We do not have to ask if the youth is married or not to encourage condom use for protection of everyone, because he may transmit infection to many persons if he had multiple relations."

-YFC PHYSICIAN, CAIRO

"You say I have to make the condom available for youth?! Is this what you call safety? It is sin! We follow what Allah says; I can't promote this in the clinic. Youth already know the condom."

-YFC PHYSICIAN, CAIRO

Providers' responses sometimes expressed an untoward attitude to certain RH issues (e.g., girls' masturbation). Providers in the studied clinics expressed conflicting views about contending with controversial problems. While most providers stated that they followed the legal and religious roles and followed the clinic protocols, some said they had conflicts in providing services for girls who were pregnant out of wedlock. They believed this is against religious beliefs and illegal, but they relied on "an ethics of justice" and had an empathetic attitude and willingness to support young women who bear the consequences of unwanted pregnancies and social condemnation.

Providers followed clinic policy and protocols without seeing a conflict in promoting condom use for young men. On the other hand, they were sympathetic to girls who are victims of sexual violence, offer them FP methods, and deal with them delicately. Moreover, they were willing to provide services to cases of Urfi marriage, but not to girls who are not married.

"I never did (provide services). Many (unmarried) girls came asking for hymenorrhaphy and termination of pregnancy. I always refuse to help them and remind them of what religion says; they know where to go."

-YFC DOCTOR, CAIRO

\section{Providers' Views on Utilization of YFCs}

All providers at YFCs reported low client flow (one case per week or even less in some clinics). Most commonly mentioned reasons for low utilization included failure of communities to realize the importance of these clinics, ineffective promotion of the clinics, and female clients feeling too shy to come to the clinics. Several physicians reported that parents discouraged their children from visiting the clinics. However, providers in some NGO clinics mentioned that with some encouragement and awareness sessions parents would allow their children to visit.

"Services are available but the youth don't seek it. They know everything from television and the Internet. Do you think they will stop engaging in risky behavior if you provide a service? On the contrary, we may be opening their eyes to things they did not know about in the first place."

$$
\text { -YFC PHYSICIAN, CAIRO }
$$

According to providers, female youth come to clinics mostly accompanied by their mothers, elder sisters, or in cases of virginity checks, by a friend, while male youth either come alone or with a friend. Girls are often stigmatized when visiting the clinic alone. Sometimes when the mother comes with her daughter to the clinic, she refuses to register her daughter's name in the files and puts her name instead.

The range of health conditions providers are consulted about by young women includes: menstrual problems, premarital concerns, vaginal discharge and infections, lower abdominal pain, breast pain, and breast size. Other problems mentioned were sexual harassment and excessive masturbation. Some female clients go to the clinic for virginity checks, 
postcoital tests, and circumcision (removal of the clitoris with or without cutting of the labia minora), while very few come for termination of pregnancy or for contraception.

Young men, on the other hand, ask about how to avoid excessive sexual desire. Masturbation, semen discharge, and nocturnal emissions (especially for unmarried men) were the most commonly reported concerns among male clients, while very few visited the clinic to check for STIs or HIV/AIDS.

\section{Providers' Communication Behavior in Relation to Sensitive SRH Issues}

The male MC was seen by male or female providers, while the female MC was invariably seen by a female provider. In some clinics, peer educators were the first persons to meet youth visiting the clinic; they referred the client to a doctor if necessary. If peers were unavailable, the social worker played this role. In other clinics, the physician is the first person who meets the client. The nurse is usually present; however, if the doctor asks to be alone with the client, the nurse is dismissed. In most of the clinics visited, only one nurse was available for many duties, such as working at the premarital counseling and FP clinic at the same time. The role of the nurse varies in different clinics, with no clear job description.

In almost half the visits conducted by the MCs, the provider welcomed the client. Others just gave the clients the name of the lab tests they needed without any counseling. The length of the consultation ranged from 2 to 45 minutes. No visual aids were used or distributed except in two clinics where the male $\mathrm{MC}$ received a pamphlet about HIV/AIDS and the female $M C$ received a pamphlet on premarital counseling.

"I went to a waiting room full of women. The nurse said, "Wait your turn to enter (to see the doctor); there's a patient with her. But the doctor refused to meet me and said (to the nurse), refer him to the social worker."

-MALE MC AT YFC, DELTA REGION

"The doctor talked to me while she was standing, and hurried me up (she wanted to leave). She reprimanded me and asked me to do a lab test and come back to see her later." -MALE MC AT YFC CLINIC, DELTA REGION

The counseling sessions were different for the male and female MCs. In three out of nine clinics, counseling was clear and nearly complete, where some providers asked the male client if he had any questions and gave him their personal cell phone numbers for any inquiries. Providers made sure that the client understood the information completely, even if he asked many times for an explanation of the matter in a clearer fashion. Time spent with the provider was also enough in those cases and the client was instructed about the follow-up visit.

However, all providers who met the MCs gave their personal opinion about what the client should or should not do; in most of the cases, this opinion was judgmental and based on the provider's own religious beliefs. Moreover, most providers did not discuss with the clients how their lives would be affected by their high-risk behaviors. Half of the providers asked the male client about symptoms and signs of STIs or infection with HIV/AIDS.

The picture was different with the female MC. The ultimate help she received was referral to a doctor to terminate her pregnancy or advice to declare her marriage. In general, the experiences of the female MC were less satisfactory; she felt insulted in some cases and said she would not advise anyone to go to these clinics. On the other hand, the male MC was satisfied with three clinics and said he would recommend the three providers to his friends.

"The doctor was so serious and cooperative; he took me to a separate room to maintain privacy. On several occasions, people would walk in and he would start shouting saying he didn't want interruption."

-MALE MC AT YFC CLINIC, CAIRO

"I am officially engaged, and the lab test confirmed that I am pregnant. The doctor replied: 'What has happened to the world, for an unmarried girl to be pregnant? I cannot do anything for you; this is a governmental hospital and I cannot take you to the operating room here."

$$
\text { -FEMALE MC, CAIRO }
$$

The clients' privacy and confidentiality was breached in many facilities. In one case, the male MC was yelled at by a doctor in the reception room in front of other people and the female $\mathrm{MC}$ was denied her request for time alone with the doctor. In the majority of clinics visited, there was no separate room for counseling. Privacy was almost always interrupted, such as in cases where other providers came into the room or when the nurse interrupted the consultation. In one of the clinics outside Cairo, the provider talked to the client in the corridor. In other cases, confidentiality was breached because the providers shared the information that the $\mathrm{MC}$ had given about himself with other providers and in one case with the social worker's son. The male client expressed his embarrass- 
ment during his visit to a governmental clinic when he had to talk in front of a group of providers sitting together before one of them moved with him to a separate room for counseling.

\section{Providers' Recommendations to Improve Quality of Services inside YFCs}

Providers offered several suggestions and recommendations for the improvement of YFC services. These included: more training; more peer educators to help in awareness raising; allocation of funds to pay for peer educators; recruiting andrologists in the clinics for male problems; and having wellequipped labs and a trained technician. One physician raised the issue of sharing in the decisionmaking process in the clinic. Some suggested changing the name of the clinic, because the name "YFCs" may be stigmatizing to young people.

"The name 'Youth Friendly Clinics' is not well understood in our culture and has to be changed. What does it mean, the doctor will be my friend?"

-PROVIDER IN NGO CLINIC, DELTA REGION

\section{CONCLUSION}

The study revealed many barriers to meeting the SRH needs of youth. The question raised at the end of the interview with providers about their needs to improve the service in YFCs has shown that health providers, on the whole, felt ill-prepared and ill-equipped to address adolescents' needs. This in conjunction with the lack of protocols and guidelines has led to shortfalls in program implementation.

The setup of YFCs is unwelcoming to youth and doesn't meet the expectations of providing considerate help. The fact that two female MCs quit because they found the experience so distressing sheds light on how someone who actually was going through a real problem would feel.

Health care providers tend to not recognize the special needs of this age group or to seek to foster a climate in which young people are supported. As a result, YFCs are often not the place where young people seek help on SRH issues.

Although many factors affect the quality of YFCs, the providers' attitude stands as a major factor affecting utilization. Our findings revealed that the providers of adolescent SRH services are located at a critical intersection between the norms and values that advocate sexual abstinence before marriage, and the reality of adolescent premarital sex and high risk behaviors that youth might face. Results from this study showed that providers strongly disapprove of adolescent premarital sexual relations and abortion, for religious and ethical reasons. A few, however, showed an empathetic attitude and willingness to support young women, who bear the consequences of unwanted pregnancies.

What is striking is that while most providers had approved of contraceptive use by sexually active males and were prepared to counsel young men on condom use, the situation was different with females, because they strongly disapproved prescribing contraceptives to them. This suggests the depth of the providers' societal norms and its effect on their attitudes.

Based on the results of the study, it is highly recommended that the starting point is building the capacity of providers, enhancing communication behaviors and changing attitudes through more education and training on adolescent SRH-related topics, and clarifying values about youth sexuality. Upgrading the quality of care inside the clinics is vital by introducing evidence-based protocols to standardize practice. Further, moving YFCs to a different setup may enhance acceptability of those services. For example, creating YFCs within the school health units could be implemented in community settings and youth gathering places, where other youth can be reached, including those at potentially higher risk and those who have dropped out of school. Another important approach is to build on innovative programs that have been initiated by some NGOs to create highly confidential programs for unmarried young people, such as telephone hotlines with referrals to health services. Efforts are also needed to address $\mathrm{RH}$ issues from a religious perspective and to involve religious leaders in the training of providers.

The results of this study highlighted several fundamental issues, yet it is important to explore other actors who may have an influence on the performance of health care providers. Exploring the views and attitudes of policymakers and the managerial bodies of the clinics to assess their commitment to youth SRH is also essential. In addition, it would be useful to conduct content analysis of the available curriculums used in training of providers to investigate the common messages delivered to them.

\section{REFERENCES}

Dejong, J., B. Shepard, F. Roudi-Fahimi, and L. Ashford. 2007.

“Young people's sexual and reproductive health in the Middle East and North Africa," Reproductive Health 14(78): 8.

Family Health International. 2009. Meeting Adolescents' Reproductive Health Needs in Egypt. Cairo: Family Health International (FHI).

Jones, R. and H. Boonstra. 2004. "Confidential reproductive health services for minors: The potential impact of mandated parental involvement for contraception," Perspectives on Sexual and Reproductive Health 36(5): 182-191.

UNFPA. 2003. State of the World Population: Overview of Adolescent Life. <http://www.unfpa.org/swp/2003/english/ch1/ index.htm>. 


\title{
SEXUAL AND REPRODUCTIVE HEALTH
EXPERIENCES OF MARRIED ADOLESCENT GIRLS
IN RURAL UPPER EGYPT
}

\author{
MANAL DARWISH \\ WAFAA HAMZA \\ MIRETTE AZIZ \\ AMIRA EL-GAZZAR
}

\section{SUMMARY}

Various social and cultural factors contribute to the prevalence of early marriage among Egyptian girls in some parts of Egypt. Married adolescent girls (MAGs) are at increased risk of adverse sexual and reproductive health (SRH) outcomes, such as sexual and gender based violence, abortion, sexually transmitted infections (STIs), and maternal and infant mortality. These risks are exacerbated by the fact that adolescent girls are shielded from information about reproduction and sexuality before marriage. The objective of this study is to understand the sexual and reproductive behaviors and experiences of MAGs in Egypt by investigating three key areas: (1) marriage experience; (2) husband-wife communication; and (3) utilization of reproductive health services among MAGs.

The research study was carried out in three villages in Assiut Governorate, in Upper Egypt, using qualitative research methods. Sources of data included 20 in-depth interviews (IDIs) with MAGs between the ages of 16 and 19 who have been married for 1-3 years, and 4 focus group discussions (FGDs) with mothers/mothers-in-law. Recruitment of participants was carried out with the help of nurses and raeda rifiya (family planning outreach workers) affiliated with the Ministry of Health and Population (MOHP). Informed consent was obtained from all participants. For MAGs who were under age 18, informed consent of a guardian (husband, mother, mother-in-law) was obtained as well.

Study results showed that desire for "protecting" the girl's reputation and virginity was the most important trigger for early marriage. Most of the participants had traumatic experiences at the wedding night when defloration was often rushed to demonstrate the girl's virginity. Problems at the wedding night were exacerbated by the fact that none of those girls received any information from their families on what to expect at the wedding night or after marriage. Several of the girls had unsatisfying sexual relations with their husbands mainly as a result of poor husband-wife communication, physical violence, the age gap, lack of knowledge, or painful intercourse. Delaying of first pregnancy was not acceptable to MAGs or mothers/mothers-in-law as the girl is required to demonstrate her fertility. Family planning use among MAGs was uncommon although not unacceptable to mothers/mothers-in-law if used for birth spacing.

Counseling services for prospective and newlywed couples are essential to address knowledge gaps and to ameliorate sexual and reproductive health problems among young couples.

\section{BACKGROUND}

Although more women worldwide are now marrying at later ages, early marriage remains the norm in some countries. Overall, 20-50 percent of women in developing countries are married by the age of 18 , with the highest percentages in sub-Saharan Africa and South Asia (Le Fevre et al. 2004). Among Egyptian women, 13 percent of 15-19 year olds and 52 percent of 20-24 year olds are married (El-Zanaty and Way
2009). Poverty, sociocultural and religious norms, civil conflict, value of virginity, and fears of premarital sexual activity are major factors that contribute to early marriage of girls (DeJong et al. 2005; Bayisenge 2009).

Early marriage is a violation of human rights because it deprives girls of freedom and the opportunity for personal development, and it negatively impacts health and well-being, educational opportunities, and participation in civic life (Bay-

\footnotetext{
*Manal Darwish is Lecturer of Public Health at Faculty of Medicine, Assiut University. E-mail: manaldarwish@hotmail.com.
} 
isenge 2009). Early marriage is generally associated with early childbearing and high fertility, both of which pose health risks for women and their children (Bruce 2003). Adolescent mothers are at increased risk of death, pregnancy-related illnesses, abortion, infertility, and exposure to sexually transmitted infections (STIs) including, but not limited to, HIV/AIDS (Fathalla 1997). Children born to young mothers have an increased risk of neonatal, postnatal, and infant mortality. They also have a risk of being prematurely born, have lower birth weights, and have lower weight gain (Chen et al. 2008).

Pregnant adolescents are at greater health risk due to the physical factors mentioned above and the health risks associated with lack of information. Moreover, large age gaps between spouses may exacerbate the young bride's disadvantage in negotiating with her husband on matters such as her health care needs, specifically SRH needs or concerns (Bruce 2003). Demographic factors, such as age, are strongly predictive of sexual difficulties. Studies have shown that sexual problems and communication issues are most common among young women married to older men. Inexperience and lack of knowledge generate stressful sexual encounters that often lead to sexual pain and potential minor reproductive trauma for young women. In the case of older husbands, erectile difficulties are common, which may lead to an uncomfortable encounter for both husband and wife.

Despite awareness campaigns and laws that prohibit underage marriage, there has been only a negligible decrease in the practice. According to the 2000 Egyptian Demographic and Health Survey (El-Zanaty and Way 2001), the prevalence of adolescent childbearing was 10 percent, almost the same as that recorded five years later in the EDHS 2005 that indicated prevalence was 9 percent. There are significant residential differences in the rates of adolescent childbearing. In rural areas, the rate (12 percent) is almost twice the rate in urban areas (7 percent). Upper Egypt has the highest rate of adolescent childbearing, especially in the rural areas (14 percent), while the level is lowest in urban governorates and urban Lower Egypt (5 percent in both areas) (El-Zanaty and Way 2009).

Adolescent motherhood is of special concern in rural Upper Egypt where women are least likely to receive antenatal care and births are generally not assisted by a trained health professional (CCA and WHO 2001). A study conducted in the Egyptian governorate of Assiut (Zarzour and Darwish 2009) showed that 38 percent of women delivered with the help of a daya (traditional birth attendant), compared with a national average of 20 percent (El-Zanaty and Way 2009).

Adolescents in Egypt have traditionally been shielded from information about reproduction and sexuality. People often gather information about SRH through trial and error, and their conclusions may not be accurate (DeJong et al. 2005). The lack of such important SRH knowledge contributes to unwanted pregnancies and a reluctance to seek medical assistance for menstrual disorders, contraceptive services, pregnancy, and delivery (CCA and WHO 2001). Little is known about the experiences of MAGs in Egypt: what problems they encounter, their practices/behaviors, and factors that influence their behavior.

\section{STUDY OBJECTIVES}

The overall objective of the study is to explore the sexual and reproductive health behaviors and experiences of young married adolescent girls in Egypt. More specifically, the study explores their experiences with regard to utilization of health services, husband-wife communication, and sexual relations. The study also aims at understanding the role of mothers and mothers-in-law in influencing the experience of MAGs.

\section{METHODOLOGY}

The target population for this study is married adolescent girls (16-19 years) who have been married for $1-3$ years and their mothers/mothers-in-law. The study was conducted in three villages in Assiut Governorate in Upper Egypt and used qualitative research methods, namely indepth interviews (IDIs) with MAGs and focus group discussions (FGDs) with mothers/ mothers-in-law.

Selection of the villages was made in consultation with officials at Assiut Health Directorate and was based on the prevalence of adolescent marriage. Nurses and family planning outreach workers (raeda rifiya) served as liaisons between the researchers and community. They assisted in recruitment of MAGs and mothers/mothers-in-law, based on the former's knowledge of the community and informal records of cases of early marriage. Directors of health units provided the research team with the space necessary for the conducting of both IDIs and FGDs at the Health Unit. Informed consent was obtained from MAGs (and their guardians) and mothers/mothers-in-law prior to any data collection.

Out of respect, the consent of the guardian of the MAG was sought first. Both the mother and the MAG were made aware if the other decided to participate in the study. The mothers included in the FGDs did not have to be matched with MAGs participating in the study. If the guardians of the MAG did not wish the girl to participate in the study, then the nurse tried to convince the guardian of the importance of allowing the MAG to participate. Conversely, if the MAG did not want to participate, her wishes were respected and she was not coerced in any way to participate. It was made clear that one participant's consent was completely independent of the other; each may decline participation independent of the other.

All individuals were assured that their participation in the study was completely voluntary and that they could withdraw during any part of the study. Privacy and confidentiality were 
also assured. Participants who could read and write were asked to sign the form. Those who could not read and write were asked to give a verbal consent while the researcher and a witness (for example, a nurse or raeda rifiya) both signed the form, indicating that the participant had been informed about the study and had agreed to participate. Data collectors received thorough training in the above procedures. Each participant received a signed copy of the consent form.

Twenty IDIs with MAGs and four FGDs with mothers/ mothers-in-law took place at the Health Unit. In all cases, the researcher ensured that the interview was conducted at a private room at the Health Unit to guarantee privacy. To protect the privacy of the FGDs and IDIs, no one apart from the research team was allowed to attend, not even the nurses who were curious and wished to attend. IDIs and FGDs were tape-recorded to ensure collecting complete information. Procedures to ensure confidentiality of information were maintained.

Each IDI lasted 45-60 minutes and covered the following topics: (1) background characteristics; (2) utilization of reproductive health services; (3) husband-wife communication; (4) sexual relations (wedding night, sexual satisfaction); (5) role of family members in decisions related to reproductive health and husband-wife relations; and (6) informational needs and preferred sources of information.

FGDs with mothers/mothers-in-law examined knowledge and attitudes in relation to: family size, antenatal care, delaying first pregnancy, contraception, birth spacing, place of delivery, premarital counseling, husband-wife relations, and sources of SRH information. The discussions were tape-recorded after obtaining informed consent from participants. The FGDs lasted 60-90 minutes.

Four IDIs and one FGD were conducted to pilot test data collection instruments and procedures. Following the pilot study, some modifications were made to the study tools. The pilot IDIs and FGDs were conducted in a village that was not included in this study but had similar characteristics to the study villages.

Data were collected by four females, two of them from the research team and two others specially recruited for this task. Because of the sensitivity of the study topic, the data collectors chosen were married females who received adequate training to address such issues. They were trained for two days using role-play, discussions, and exercises on developing open-ended questions and obtaining informed consent. The FGDs and IDIs were transcribed by the data collectors within 24 hours. Names of participants were replaced by initials in the transcripts; digital recordings were erased after transcription to ensure confidentiality.

Researchers faced a number of challenges during the data-collection period. These included the inability to conduct research in some of the villages recommended by the Assiut health directorate because of security issues emerging after the Revolution of January 25th. A few participants withdrew from the study due to husband's refusal. It was difficult to obtain guardians' consents if the MAG was less than 18 years of age. Accordingly, FGDs and IDIs were conducted in parallel, in order to have either mother or mothers-in-law present at the same time to sign guardians' consent forms.

Determining the MAG's actual age and age at marriage was difficult because of the lack of official documents. Many feared revealing their actual age because of the recent law that raised the minimum age of marriage to 18 in Egypt. The researchers, hence, asked different verification questions before beginning the interview.

\section{RESULTS}

\section{Participant Demographics}

As shown in Table 6.1, the average age of MAGs was 18.4. Education ranged from no schooling to completed secondary, where one-fifth of participants had no schooling at all and one-third had completed their secondary technical education. All participants were not working for cash. The marital engagement duration ranged from 0-30 months, with an average engagement duration of 9.5 months. The average duration of marriage at the interview time was 20.9 months, during which an average of 1.3 pregnancies occurred. Only one of four participants did not get pregnant until interview time despite being married for more than one year. The average age at first pregnancy ranged from 15-18 years, with a mean of 16.7 years.

\begin{tabular}{|c|c|}
\hline Characteristic & Number of participants \\
\hline \multicolumn{2}{|l|}{ Current age (years) } \\
\hline 16 & 1 \\
\hline 18 & 9 \\
\hline 19 & 10 \\
\hline \multicolumn{2}{|l|}{ Education } \\
\hline Illiterate & 4 \\
\hline Primary & 6 \\
\hline Intermediate & 3 \\
\hline Secondary & 7 \\
\hline \multicolumn{2}{|l|}{ Occupation } \\
\hline Not working for cash & 20 \\
\hline Working for cash & 0 \\
\hline Total & 20 \\
\hline
\end{tabular}


The total number of mothers and mothers-in-law participating in the study was 40 . Their age ranged from 35-70 years, with an average of 49.6 years. The majority of mothers and mothers-in-law (67.5 percent) had never been to school, about 20 percent had completed their secondary technical education, and the remaining 12.5 percent dropped out of school either at elementary or intermediate levels of education. The majority of mothers/mothers-in-law were not working for cash, and those who did (only 17.5 percent) were mainly government employees.

\section{Reasons for Early Marriage}

The majority of the mothers/mothers-in-law agreed to early marriage of girls. Further discussions revealed that ensuring the girl's virginity and the concept of protection of the girl were the most important triggers, followed by appearance of a suitable person and the saving of the girl's reputation. Among the popular reasons repeatedly mentioned by participants was the notion that the younger the girl is at marriage, the better her chances of having children.

"If the girl reaches 30 years, it's over.... She cannot conceive any more...excuse me...her ovaries shrink."

-MOTHER

Many participants referred to a feeling of pride, which parents sense in rural areas when their daughters marry early, especially if the girl is already out of school. Some participants referred to the social pressures posed on the girls themselves if they are not married, and others mentioned economic reasons as factors favoring early marriage.

"Here, villagers like to show off by getting their girls married earlier than their peers.... They say my daughter is as old as yours and she got married earlier."

-MOTHER

"The repeated external talks about a girl's delayed marriage put the girl and her family under severe pressure, to the extent that she would come home in tears."

\section{-MOTHER-IN-LAW}

Early marriage is still viewed by mothers and mothers-inlaw as a social security issue and a means for girls to complete their family formation while they are still young.
"She gives birth to a baby and two while she is still young.... Whatever the number of children she gives birth to, she remains young."

-MOTHER

On the other hand, participants expressed some perceived disadvantages to early marriage, such as exposure of girls to pregnancy complications, deterioration of girls' health, and immaturity of reproductive system that leads to more complications. They also stated that early marriage is associated with higher rates of school drop-out, longer fertility periods, higher probability of divorce while still young. In addition, they mentioned the girl's social and psychological immaturity that makes her incapable of carrying out the responsibilities of marriage.

\section{Engagement and Husband-Wife Communication}

Analysis of MAGs' reports showed no clear pattern for the engagement period. which varied from a couple of days to a couple of years. Interestingly, duration was not related to how much the participant felt familiar with her husband at the time of marriage. The difference in age between the participant and her husband varied from 1 to 45 years. A few of the girls had more than a 35-year age difference with their husbands.

"I didn't know him. Actually I was working on the cotton field, he asked my father to marry me, he brought the gold and three days later we got married."

$$
\text { -MAG, } 18 \text { YEARS }
$$

A clear relationship was found between good husband-wife communication and participants' education level, and age gap between spouses. Husband-wife communication problems were found in cases with either large age gap, participants' self-perception of being young and lacking experience, or violence inflicted by the husband.

"It's justified for him not to consider my opinion as I have little experience in life."

-MAG, 18 YEARS

\section{Premarital Information/Advice}

When asked about their sexual knowledge before getting married, the majority of MAGs admitted to having no information or having no one to talk with about sexual relations or what is 
expected to occur after marriage. They attributed it to the fact that the whole issue is considered taboo, especially in rural areas. The only pieces of advice they were sure to receive from mothers and relatives were mainly related to their duties toward their husbands and their homes. A few participants reported being informed about sexual issues by close relatives, but never by their mothers. All MAGs said they would have liked to be informed about how to prepare for the wedding night and how to communicate with their husbands.

"They should have told me many things especially about the wedding night.... When they came on next morning, I cried to my aunt and told her, "You should have told me about sexual relations. I didn't know how and why they do this. Marriage is not just eating, drinking, and doing house chores. We should share our lives." -MAG, 18 YEARS

Most mothers/mothers-in-law did not talk about sexual issues with their daughters before marriage because they thought girls knew all about sexual life from media and friends. They expressed the need for premarital counseling services provided by a female physician to help raise their girls' knowledge of these matters. The currently available sources were other relatives, older sisters, and friends.

\section{Sexual Relations}

The majority of MAGs had their defloration done through sexual intercourse. Few of the participants had undergone the traditional method of defloration (that is, manual defloration by a traditional birth attendant) with or without witnesses. Almost always showing evidence of defloration was still required immediately, which led to fear, worries, pressure, and even violence to get defloration done quickly.

“It was a strange feeling. I didn't feel at home... I got more scared when I saw five people staring at me, namely: daya, his sister, my sister-inlaw, and her sister. I felt as if they will slaughter me this night... He didn't talk to me. They took off my dress and sat me down on the floor. Then it happened."

-MAG, 18 YEARS

Most of the mothers/mothers-in-law agreed that the traditional method of defloration was no longer used, except in some areas. However, they noted that showing that defloration is completed is still required immediately to prove virginity of the girl and potency of the husband.

"Sometimes the husband has to give her a drug to make her sleep. Unless he drugs her, he can't manage to sleep with his bride as she is very scared."

-MOTHER

When MAGs were asked about satisfaction with sexual relations with their husbands, 9 out of 20 mentioned dissatisfaction either sometimes or most of the time. This was mostly attributed to the lack of communication and lack of concern from their husbands about their feelings. Other causes of dissatisfaction were attributed to physical violence, the age gap, and lack of knowledge or painful intercourse. Only those who were satisfied with their sexual relations said they would ask for sex using indirect/direct remarks. Others did not because of lack of desire, violence, or because they considered requesting sex as taboo.

"My daughter usually sleeps besides me. Once she fell asleep, he rushes to sleep with me quickly and after he finishes he turns his back to me and falls asleep.... I need him to cuddle me and do foreplays, otherwise it's pain not pleasure."

$$
\text { -MAG, } 19 \text { YEARS }
$$

When mothers/mothers-in-law were asked about commonly occurring problems resulting from sexual relations, the majority mentioned: bleeding, injury, fears and worries, and impotence mainly due to anxiety. However, all agreed that none of these problems could be attributed to being young, except for lack of knowledge. They also mentioned drug use as a precipitating factor for such problems. Still, some participants found no reason for problems to occur, especially if the girl had agreed to the marriage and knew her husband well.

\section{Delaying First Pregnancy}

None of the MAGs intended to delay their first pregnancy because the vast majority wanted to get pregnant immediately. Misconceptions regarding lower probability of conception during adolescence were among the mentioned reasons for not using contraception. They also referred to social pressure, especially posed by the mother-in-law and the husband, lack of knowledge about healthy timing of pregnancy, or feeling lonely as reasons for not wanting to delay first pregnancy. 
“I'm living with my mother-in-law ... it was a catastrophe when I didn't get pregnant for three months. He is the only son and she wanted to see his children soon. She kept pushing me to visit the doctor or even a traditional healer (Sheikh)."

-MAG, 18 YEARS

Nearly all mothers and mothers-in-law reject the idea of delaying the first pregnancy either because they needed to be assured of the couple's fertility or for fear of method-induced infertility. It was only accepted in cases when the girl was still in school or when the husband and wife agreed to this decision. In general, mothers/mothers-in-law didn't mind spacing, but this could be done or thought of after the first pregnancy. According to almost all participants, husbands would refuse to delay the pregnancy, but in a few cases they said they would accept for financial reasons.

"We like them to get pregnant immediately after marriage. For example, when my daughter got married, I was very worried and kept asking her every single month if she missed her period or not... I want her to get her first baby, then she is free to wait for whatever period... I want to make sure that she is able to conceive." -MOTHER

"If she doesn't want to get pregnant, her husband won't keep her. He will kick her out and remarry... If she is not willing to have a baby, this means that she does not want her husband."

\section{-MOTHER-IN-LAW}

\section{Reproductive Health Services Utilization}

All MAGs received some sort of maternal health care services. The vast majority attended one or more antenatal care visits regardless of socioeconomic and demographic characteristics and husband-wife communication factors. All mothers/ mothers-in-law agreed to the importance of antenatal care especially for young girls, because pregnancy may be more risky for them; the only reason given for not utilizing the services was economic. They received the antenatal care services at a hospital or private clinic but not a public health clinic, which they mainly used for receiving tetanus toxoid vaccina- tions. Also, the vast majority of the participants had deliveries assisted by a skilled person in a hospital except for a few who had witnessed bad hospital experiences among their relatives and thus insisted on delivery at home with the help of a daya (traditional birth attendant).

"I went to a hospital with a sister... she was in labor and dying. I swear the doctor slapped her... I saw this with my own eyes, and the delivery position with her legs spread apart... It was very embarrassing." -MAG, 18 YEARS

Hospitals were the preferred sites mentioned by the majority of mothers and mothers-in-law for provision of antenatal care and delivery services. The role of health units was limited mainly to tetanus toxoid vaccination as mentioned by all participants and for receiving antenatal care services for those with limited economic abilities. Few participants mentioned private clinics as sites for receiving antenatal care services. When asked about preferred sites for delivery, a number of participants mentioned hospitals, however after the traditional birth attendant's preliminary assessment of the route of labor.

Family planning (FP) methods were used by few participants, mainly after the first child. Those participants were characterized as being relatively better educated, of high socioeconomic status, and having good husband-wife communication. Others did not use any method or used it inconsistently. The main reasons stated for not using FP methods were those related to misconceptions, such as improper use of breastfeeding as an FP method, or fear of method-induced infertility. Husband refusal and social pressure came next in the list of reasons for not using FP methods.

Most mothers/mothers-in-law had positive attitudes toward FP. They accepted FP for spacing after delivery of the first baby. Wanting a boy child came at the top of the list of expressed reasons for not using FP. This was followed by lack of knowledge about FP methods, social security for the married girl, misconceptions, and husbands' refusal.

\section{CONCLUSION}

Early marriage is deeply entrenched in rural Egyptian culture. Concepts such as "girl's protection" or social security and "preserving a girl's reputation" continue to be the most important triggers for this phenomenon. Clearly, girls do not receive any information about sexual relations prior to marriage. Apart from the wide array of SRH risks this may expose them to, it consequently leads to the vast majority of girls getting pregnant once married and facing another set of risks altogether. In addition, communication is lacking between husbands and 
wives and this is linked to a series of consequences, including dissatisfaction in sexual relations, and sometimes painful intercourse and physical violence. Although agreement was unanimous on rooting out the traditional method of defloration, there was still insistence on publicly proving the virginity of the girl and the potency of the husband on their wedding night, emphasizing the power of cultural norms to which interventions should be extremely sensitive.

Based on the results of this study, several recommendations are proposed. The main two areas to be addressed are supporting the delay of age of marriage and providing adequate support to married girls. The former may be achieved by assuring that girls' school attendance is protective of their reproductive health, fostering delayed marriage, and developing meaningful policies regarding registering marriages and enforcing laws concerning minimum age at marriage. An important approach is to work closely with religious leaders, parents, and others who shape community norms to discourage marriage below the legal minimum age. Further, it is imperative in rural areas to enhance public awareness of the risks to mothers and children posed by early marriage. It is also important to adopt specific strategies to help girls make the transition to marriage as safely as possible, such as promoting voluntary counseling among those couples who are newly married or are contemplating marriage. Emphasizing the importance of husband-wife communication and shared decision-making during counseling sessions as well as encouraging mother-daughter communication on $\mathrm{SRH}$, especially in preparation for marriage, are also key strategies.

Also needed are strategies to assist young mothers in delaying first birth and supporting first-time mothers. Programs must consider the limited mobility of MAGs in order to design socially acceptable means to provide needed information, social connections, and services. The study found that mediaradio and television-should be used to convey messages and diffuse new ideas. Mass media should encourage delay of age of marriage, delay of first pregnancy, and dispel rumors and misconceptions about FP. Moreover, a crucial step is to train primary-care providers in couple counseling and management of common sexual problems and to ensure access to emergency obstetric care at the rural health unit. Finally, operations research is needed to test the efficacy of different interventions to delay age of marriage and to support married adolescent girls.

\section{REFERENCES}

Bayisenge, J. 2009. Early Marriage as a Barrier to Girl's Education: A Developmental Challenge in Africa. <www.ifuw.org/ fuwa/docs/Early-marriage.pdf $>$.

Bruce, J. 2003. Including Married Adolescents in Adolescent Reproductive Health and HIV/AIDS Policy. Geneva: World Health Organization.

CCA and WHO. 2001. Common Country Assessment, Egypt final draft.

Chen, X. et al. 2008. “Increased risks of neonatal and postneonatal mortality associated with teenage pregnancy had different explanations," Journal of Clinical Epidemiology 61(7): 688-694.

DeJong, J. et al. 2005. "The sexual and reproductive health of young people in the Arab countries and Iran," Reproductive Health Matters 13(25): 49-59.

El-Zanaty, F. and A. Way. 2001. Egypt Demographic and Health Survey 2000. Cairo, Egypt: Ministry of Health, El-Zanaty and Associates, and Macro International.

Egypt Demographic and Health Survey 2008. Cairo, Egypt: Ministry of Health, El-Zanaty and Associates, and Macro International.

Fathalla, M. 1997. From Obstetrics and Gynecology to Women's Health: The road Ahead. Parthenon Pub Group.

Le Fevre, J. et al. 2004. Future Options Foreclosed: Girls Who Marry Early. Drawn in part from 2001 UNICEF report "Early Marriage, Child Spouse."

Zarzour, Ali and Darwish, Manal. 2009. “Assessing the Current Situation of FP, Maternal and Child Health Intervention on Quality of Health Services, Neonatal and Maternal Mortality and on FP Usage in Abnoub District, Assiut." Unpublished report. Assiut, Egypt: Save the Children. 


\title{
7 "IF SHE IS RESPECTABLE, NO ONE WILL HARM
HER": ATTITUDES OF EGYPTIAN YOUNG MEN
TOWARD SEXUAL HARASSIMENT OF WOMEN
}

\author{
MONA HASSAN \\ OMNIA MEHANNA \\ ALAA SAMRA
}

\section{SUMMARY}

Research evidence indicates that sexual harassment is highly prevalent in Egypt, especially in urban areas. Among the Egyptian women surveyed in Cairo, 83 percent said they had experienced sexual harassment (ECWR 2008). Similarly, a nationally representative survey of young people in Egypt conducted by the Population Council showed that almost half of girls aged 10-29 experienced sexual harassment (Population Council 2011). The high rate of harassment in Egypt points to larger problems in gender relations and male attitudes toward women. Thus the issue needs to be thoroughly explored from the perspective of men, as they are usually the perpetrators.

The present exploratory study was conducted to address the gap in knowledge about male attitudes and perspectives toward sexual harassment of women. The study's aims were to: (1) examine gender attitudes of young men and opinions regarding sexual harassment; (2) explore the reasons or motivations for sexual harassment; and (3) provide recommendations for future interventions to decrease the occurrence of this behavior.

To achieve these goals, a qualitative research approach was used. A sample size of 30 males between the ages of 18 and 24 years was studied using in-depth interviews (IDIs). Participants were from Greater Cairo, which is believed to have the highest incidence of sexual harassment in Egypt. Youth were recruited from coffee shops in Maadi, Tahrir Square, and Zeinhom areas in Cairo. Informed consent of the males participating in the IDIs was obtained before conducting interviews.

The study showed that the majority of youth have either harassed women or have friends who have harassed women through words, staring, and less commonly touching. Youth tend not to see harassment as a form of abuse, but as an acceptable means of flirtation that is even "enjoyed" by some women. Reasons that young men gave for sexually harassing women were seeking a sexual outlet, achieving sexual pleasure, and complying with peer pressure. A number of participants justified sexual harassment and gender-based violence as a response to provocation, be it intentional or not, thus shifting responsibility to the female.

The study revealed highly conservative gender norms among young men. Several of them encourage limited female education (up to secondary education) to preserve an upper hand and affirm superiority in their relationship. In addition, in many cases, employment was only encouraged if it did not interfere with men's perceived rights and needs, emphasizing that wives should be home before their husbands to respond to their needs.

Interventions to stop sexual harassment should promote positive attitudes toward women through mass media, schools, and religious institutions. There is also a need to raise public awareness of the problem of sexual harassment as a serious social issue that has negative implications for both men and women.

*Mona Hassan, Obstetric and Gynaecology Consultant, Al-Mansoura General Hospital. E-mail: drmonahassan@hotmail.com. 


\section{BACKGROUND}

Unwanted sexual attention has historically been commonplace in many social settings and public places, namely in schools and the workplace. Sexual intimidation, sexual coercion, and sexual exploitation are often precursors to more aggressive unwanted sexual advances (Rowe 1996). Because it is a new concept, interpretations of the occurrence and severity of the phenomenon still vary widely. Conceptualizations of sexual harassment are influenced by gender, class, environment, and levels of education. Even the definition of sexual harassment remains ambiguous in the literature (Powell 1983; Timmerman and Bajema 1999).

Sexual harassment is defined as any unwanted attention or behavior of a sexual nature that an individual experiences, such as inappropriate comments. One of the most widely used definitions of sexual harassment in the United States includes acts such as gender harassment expressing hostile, insulting, or degrading attitudes against women (Fitzgerald and Shullman 1993). The UN Office of the Special Adviser on Gender Issues and Advancement of Women (OSAGI), defines sexual harassment as, "Any unwelcome sexual advance, request for sexual favor, verbal or physical conduct or gesture of a sexual nature, or any other behavior of a sexual nature that might reasonably be expected or be perceived to cause offence or humiliation to another" (Office of the Special Adviser on Gender Issues and Advancement of Women 2010).

Sexual harassment can take many forms and be observed in many different places. For the purpose of this research, three forms of sexual harassment (visual, verbal, physical) will be identified as they relate to harassment in public, not in the workplace.

Visual harassment can be in the form of explicit photographs, images, or graffiti; lewd gestures; and pornographic correspondence, such as letters or emails of an inappropriate nature. Verbal harassment includes diminutive name calling, referencing one's sexual organs, sexual jokes, inappropriate comments about one's body, expressing unsolicited sexual desire, discussions about someone's sexual activity, sexual intimidation, sexual sounds and noises, and "catcalling." As for physical harassment, this includes any kind of unsolicited and unwanted touching, brushing, groping, pulling, patting, or rubbing of any sort, but especially that with sexual motivation. Standing too close to someone and purposefully rubbing or pulling on clothes, or embracing someone, are also forms of physical harassment.

The Arabic term for sexual harassment, al taharush al ginsi, has only been in use since the mid-1990s. There is evidence that the incidence of sexual harassment is high in Egypt, with the incidence found to be substantially higher in urban and informal urban settings compared with rural areas (Population Council 2011). On a daily basis, 60 percent of
Egyptian women reported experiencing harassment, and 98 percent of foreign women reported the same experience (Ammar and Mayton 2008). Sexual aggression is experienced by both foreign and Egyptian women.

It is noteworthy that women from all social and religious groups are often blamed for sexual harassment because they do not conform to conservative Islamic dress codes. However, anecdotal evidence indicates that both veiled and unveiled women experience the same amount of harassment.

Youth in Egypt have little or no access to sexuality-related information and education, thus it is not a surprise that sexual harassment of women is a serious problem in Egyptian society (Ragab 2009). Moreover, limited information exists regarding the male perspective on the phenomenon. The studies conducted in the West have consistently found males more likely than females to sexually harass their peers (Bryant 1993; Lipson 2001), but why do men harass women? This question has received considerable attention from academics in a variety of fields (Stillman et al. 2009). Harassment in Egypt has been viewed as a minimal social problem that politicians and the media have tended to treat as random abnormal events, despite its prevalence. Because of the larger perception of harassment as an isolated aberration from proper social norms in Egyptian society, there is not a perception of a pressing need to confront the behavior (Atassi 2009).

This study adds to growing public awareness about sexual harassment on the street-the most common form of harassment in Egypt-and subsequently to increased response to the problem. With increased awareness and greater response to the problem, sexual harassment will cease to be viewed as isolated acts of perversion, and instead as components of a pressing social problem.

\section{STUDY OBJECTIVES}

The overall objective of the study was to explore the perceptions and attitudes of young men toward sexual harassment of women, namely: (1) examine gender attitudes of young men and opinions regarding sexual harassment of women; (2) explore the reasons or motivations for sexual harassment; and (3) provide recommendations for future interventions to decrease the occurrence of this problem.

\section{METHODOLOGY}

Due to the exploratory nature of the subject, a qualitative study was conducted, using IDIs with young men in Cairo. IDIs were conducted because of the lack of sufficient data on the topic and because IDIs are useful in probing for answers. Data was collected from a sample of 30 young men recruited from three different parts of Cairo, since Cairo is assumed to have the highest incidence of sexual harassment in Egypt. 
The sample was recruited from coffee shops in Maadi, Tahrir Square, and Zeinhom. The researchers visited cafés located in these areas and approached the youth visiting the cafés to inform them about the study and get their approval to participate. Two male members of the study team conducted interviews during April and May 2011. After obtaining participant's approval, the researcher would move to a private table to conduct the interview. Some participants were reached through friends and informed about the study, and if they approved a date was scheduled for the interview. Interviews were conducted mainly in the evening to ensure high turnout of young men. The interviews lasted about an hour each.

The main challenge of the study was participant recruitment. For every two males approached for the study, only one accepted. Participants who declined to be interviewed mentioned the following reasons: lack of time, issue was too personal, it was not a suitable time to talk about harassment after the revolution, and/or the topic did not deserve much attention. Other challenges included time needed to explain the study to participants and obtain their informed consent (at least 20 minutes) and refusal of some participants to have their conversation tape-recorded.

Interviewers maintained privacy by ensuring that participants were not in any way overheard by other customers or waiters. Most interviews were tape-recorded. No personal identifiers were recorded on the audiotapes or transcripts.

Since the study was carried out shortly after the Revolution of January 25 , there was difficulty obtaining approvals from NGOs to assist with the recruitment of participants. Therefore, this approach was eliminated and the researchers relied on direct methods of recruitment.

Pilot testing was conducted with four male participants to assess clarity of questions and appropriateness of data collection procedures. Some questions were eliminated because they were redundant, while others were added, namely participant's opinions on gender segregation in school and opinions on women's perceptions of harassment. Wording of some questions was changed. For example, the phrase "making a special relationship with a woman" was used instead of the phrase "making a sexual relationship with a woman."

\section{RESULTS}

\section{Socio-demographic Characteristics}

Participants were young adult males aged 18-24 years. More than two-thirds of study participants were 21 years of age or older (67 percent), and the majority were single (87 percent). About half of the participants were attending (or had attended) university and an equal number of participants were attending (or had attended) secondary school. None of the study participants had a lower level of education.
About two-thirds of participants reported attending coeducational institutions at one stage of their life. The remaining one-third had either attended coeducational or segregated schools all their life. Four out of five participants were either students or working. The remaining 20 percent were unemployed, with the exception of one participant who had retired due to a disability incurred while working. About half of participants (43 percent) reported having a troubled relationship with their parents, mainly communication problems with their fathers.

\section{Gender Attitudes}

Participants were asked about their attitudes regarding women's rights to education. The majority expressed their acceptance of women's education up to obtaining a secondary degree. Several participants stated that they found no need for women to continue their studies beyond secondary education, whereas others believed that girls showed inappropriate behavior at universities. It is interesting to note that whereas the majority of participants admitted that women had the right to education, they still believed that a woman should be allowed to study mainly to be able to communicate better with her husband and to be a good mother.

"I approve of girls education but up to a limit, such as obtaining a diploma only, but a boy should continue his education to have an upper hand over his woman."

-YOUNG MALE PARTICIPANT, GREATER CAIRO

Women's right to work received much less support from participants, who believed that it is better if women stayed at home to take care of their children and to carry out their household duties. Those who approved of women's right to work stressed that household duties and childcare should come first. Several participants placed restrictions on women's work, such as not working late hours or working only in certain professions, like being a doctor or a teacher.

"Women's work should depend upon the family situation, like children's needs, and she should work in the same field of her studies and show progress in her job, while the man is supposed to be responsible for the household expenses." -YOUNG MALE PARTICIPANT, GREATER CAIRO

Among those who disagreed with women's right to work, some stated that it is acceptable for women to work but they have to resign when they get married. Others were opposed because they did not want their wives working in a mixed- 
gender work environment or because they believed that employment of women was an underlying reason for men's unemployment.

There was no agreement among participants regarding gender segregation in educational settings. While some supported gender-segregation in all educational levels to avoid distraction by the opposite sex, other participants accepted co-ed schools up to primary level. Those who were opposed to gender segregation in schools argued that this would allow boys and girls to interact with one another in a natural environment and to stop seeing each other as sex objects.

"It is better to have coeducational institutions to encourage competition. As for harassment, it depends on the girl herself: if she is respectable, no one will harm her. It also depends on the culture of the students and their opinions regarding girls and mixed-gender education."

-YOUNG MALE PARTICIPANT, GREATER CAIRO

On a related issue, most participants believed that there should be gender segregation in public transportation to protect women and decrease their exposure to harassment. Those who disagreed stated that there should be a genderequality policy, while sexual harassment in public transportation should be addressed.

"I strongly support the idea of gender segregation in public transportation to avoid harassment during rush hours."

-YOUNG MALE PARTICIPANT, GREATER CAIRO

Almost all participants believed that there should be a curfew set for women to protect them against possible risks associated with late hours and to safeguard their reputation. The time limit ranged from 6 p.m. to 11 p.m., while some participants added that in all cases married women should be home before their husbands in order to fulfill their needs.

"Of course she should be home by 8 or 9 p.m. at the latest, and I object to a job that would require her to come home late."

-YOUNG MALE PARTICIPANT, GREATER CAIRO

Most of the participants stated that they do not approve of men beating the women in their families, for example their wives or sisters. On the other hand, a few justified violence against women as a means of discipline. Participants seemed more accepting of verbal than physical violence, while two participants believed that insults could be more detrimental than physical violence.

"If she talked on the phone at a late hour, or if she is speaking to someone he doesn't know, or if she came home at a late hour, the right thing to do is beat her, not talk with her."

-YOUNG MALE PARTICIPANT, GREATER CAIRO

\section{Attitudes and Experiences of Sexual Harassment}

Participants were asked to state their agreement or disagreement with a number of statements related to sexual harassment. The majority of participants did not think that "innocent flirtations made the day interesting." Also, most participants did not think that "attractive females should expect sexual advances."

Discrepancy in participants' responses was noticed when they were asked if they thought women enjoyed sexual harassment. More than half of participants believed it depended on the woman and the situation (that is, some women do enjoy being sexually harassed), whereas only a few participants believed that women do not like to be sexually harassed.

The majority of participants stated that they knew men who harassed women and admitted harassing women themselves. Flirting, touching, and staring were the most commonly mentioned types of sexual harassment practiced by participants or their friends. They described it as normal, innocent flirtation, and it was just for fun. Only two participants admitted to more serious incidents such as grabbing a girl on a microbus, touching the breasts of a girl, or participating in group sexual harassment.

"As for sexual harassment, just two hours ago I grabbed a woman while she was getting on the microbus... But she is the one responsible for this, because her gaze was inviting to me... I also know her."

-YOUNG MALE PARTICIPANT, GREATER CAIRO

Interestingly, participants described the profile of someone who frequently harasses women as being: a teenager, uneducated, unemployed, not brought up well, lacking self-respect, not religious enough, sexually repressed, alcohol or other substance abuser, and psychologically ill.

Participants were asked to state whether they agreed with a list of possible reasons for sexual harassment. Reasons 
more likely to be accepted by participants were: getting some sexual pleasure; peer encouragement and pressure; seeking a sexual outlet, especially in case of sexual deprivation (for example, lack of financial means for marriage, or having a marital problem); boredom; and need for excitement.

Participant-identified characteristics of women most likely to be sexually harassed were described as: being pretty, wearing attractive clothes, wearing excessive makeup, walking or looking at men in a provocative way, or working in a job that involves dealing with men (for example, customer service).

"Of course it is because of the way the woman talks! This and the way she dresses are the two main factors. We can excuse the man's behavior, as the woman is the reason."

-YOUNG MALE PARTICIPANT, GREATER CAIRO

\section{Reactions to Sexual Harassment Incidents}

All participants reported that they had witnessed incidents of sexual harassment in the past. However, the majority stated that they did not take any action to stop it either because it was not their business or because they did not want to get in trouble. A few of the participants believed that the harassed woman enjoyed it or did not look respectable enough to merit interference on her behalf. However, participants would act differently if they witnessed a female relative being sexually assaulted.

"I have witnessed only 'usual' harassments. However, if I witness a sexual harassment (assault), I will intervene and help the woman." -YOUNG MALE PARTICIPANT, GREATER CAIRO

All participants agreed that society does not deal with different types of sexual harassment in the same way. Staring and flirting are generally accepted by society, while touching, grabbing, bullying, and exposing sexual organs are types of harassment that are rejected by society.

\section{Suggestions to Stop Sexual Harassment}

Participants suggested a number of strategies for women to use to avoid sexual harassment. With verbal harassment, most participants thought that the best thing a woman could do if she is being sexually harassed is to ignore the harasser. However, one participant said the opposite; when the woman ignores the harasser, he could take it as a sign of acceptance to continue. Scolding the harasser and shouting at him was considered by most participants to be effective, while some participants disagreed, saying it will not make a difference as most harassers are determined to continue regardless of the woman's reaction. Moreover, few participants warned against scolding or shouting at the harasser, saying it could aggravate him. Asking for help was considered the best strategy in case of physical harassment. When asked whether passersby would respond to her call for help, participants confirmed that they would. In addition, some participants thought that women should have a means of self-defense (such as pepper spray), and one participant suggested that women should practice some combat sports to learn how to protect themselves.

"She (the woman) should yell at him (the sexual harasser) and hit him, but if it is only verbal harassment then she shouldn't respond to it, but should treat him as a barking dog." -YOUNG MALE PARTICIPANT, GREATER CAIRO

Some participants believed that there is no benefit to reporting the incident, not even to the woman's family. More than half of the participants thought it was useless for the harassed woman to report the incident to the police, because the police officers do not take these complaints seriously. One participant even warned that policemen might sexually harass a woman who approaches them to file such complaints. Others were skeptical of the value of filing such complaints, wondering how the police officers would reach the sexual harassers if their identities were unknown to the women filing the complaints.

"She (the woman who has been sexually harassed) shouldn't complain about it, not even to her mother!"

$$
\text { -YOUNG MALE PARTICIPANT, GREATER CAIRO }
$$

“The police won't take the complaint against sexual harassment seriously, even after the revolution has taken place."

$$
\text { -YOUNG MALE PARTICIPANT, GREATER CAIRO }
$$

Regarding laws criminalizing sexual harassment, only three participants doubted the efficacy of these laws, as two of them considered the deterring factors to be men's awareness and upbringing. One participant felt that sexual harassment is addictive, and even if laws exist to criminalize it, those who are addicted to it will continue committing it. Most participants did not support criminalizing verbal harassment and thought that only perpetrators of physical harassment should be convicted. Other participants believed that a verbal harasser should be 
punished only if the harassment is in the form of an obscene explicit sexual remark.

"There should be (criminalization of sexual harassment) but verbal harassment shouldn't be criminalized, only physical harassment." -YOUNG MALE PARTICIPANT, GREATER CAIRO

Participants did not agree on the types of punishment that should be given to sexual harassment perpetrators. Some thought there should not be a severe punishment so as not to jeopardize the future of those who were found guilty. Others thought a fine would be appropriate, while a number of participants thought that punishment should include spending a period of time in jail. Interestingly, the vast majority of participants discussed criminalization of sexual harassment as if they were proposing a new law; only two of them knew that such a law already exists.

\section{CONCLUSION}

The results of this study tend to explain the high prevalence of sexual harassment in Egypt. With the majority of participants declaring that they have exercised sexual harassment and a good portion believing that women enjoy being harassed, it is safe to assume that the numbers will keep rising unless drastic measures are taken.

The study sheds light on the most common gender attitudes against women, as society places the blame solely on the way women dress and behave thus freeing men from any responsibility. The study also reveals how the phenomenon is viewed with sheer indifference, with the suggestions for simple solutions such as segregating women and men on public transportation as opposed to tackling the problem from its roots. Females continue to be objectified and considered sexually provocative. Interestingly, the study reveals that many men prefer limited education for women to maintain male superiority. As such, it can be deduced that female empowerment via education is not desirable and prevalent enough to put an end to this occurrence.

To date, many Egyptians are not aware that sexual harassment is a criminal offense, punishable by law. Along with the lack of trust in police authorities to take necessary action, this leads to less incidents being reported and more acceptance by the society.

Based on the study findings and participants' opinions, several recommendations have been developed. The problem should be addressed from the roots starting with ingrained attitudes toward women in general. Objectifying women as a source of seduction and sexual attraction, and restricting their freedom of expression, such as being considered "fair game" based on the way they choose to dress, should be eliminated if the coming generations are to believe in and practice gender equality. Attaching a lot of gravity to a family's reputation based on a female member's behavior and entitling the male members to discipline her for misdemeanors can only result in further infringement on the female's autonomy and independence, portraying her as a weaker, inferior being.

Measures to alter societal attitudes about women include conveying messages through mass media, school curriculums, religious institutions, and other venues. By the same means, women's legal rights to press charges against harassers and how to access these rights should be made known. Accordingly, police officers should take the issue of sexual harassment seriously and firmly reinforce the law to prevent further spread and normalization of the phenomenon. Similarly, religious leaders, preferably young ones, should be encouraged to speak freely about sexual harassment and the religious implications for those who commit it.

There is an urgent need for mass-media awareness campaigns about sexual harassment and its consequences. Efforts are needed to dispel myths such as that women enjoy or deserve sexual harassment. Policies encouraging coeducation at most levels are recommended, as this will normalize the relationship between boys and girls in a natural environment.

The results cited in this study represent at best a beginning to the process of understanding and defining sexual harassment. This preliminary study contains information that may be interesting and useful. However, much more research is needed before the phenomenon of sexual harassment can be fully understood and consequently our ability to prevent this public health problem can be furthered. A study that can identify females' perceptions and attitudes toward sexual harassment and describe the experience of women who have been exposed to incidents of sexual harassment would be of crucial importance. Studies exploring how religious leaders, mass media professionals, and police officers view the phenomenon of sexual harassment, and the best strategy to control it, are also important to conduct.

\section{REFERENCES}

Ammar, M. and J. Mayton. 2008. "60 Percent of Women Harassed on a Daily Basis-Cairo: Protective Laws Unfit for Women on Streets in Cairo." <http://womennewsnetwork. net/2008/10/09/womenharassedcairo807/>.

Atassi, M.A. 2009. "Taking on sexual harassment, a social phenomenon in Egypt," Al Jadid 15(60).

Bryant, A. 1993. "Hostile hallways: The AAUW survey on sexual harassment in America," Journal of School Health 63(8): 355-357. 
Egyptian Center for Women's Rights (ECWR). 2008. “Clouds in Egypt's Sky" Sexual Harassment: From Verbal Harassment to Rape." <http://www.preventgbvafrica.org/content/ clouds-egypt $\%$ E2\%80\%99s-sky\%E2\%80\%9D-sexualharassment-verbal-harassment-rape>.

Fitzgerald Louise, F. and Sandra L. Shullman. 1993. "Sexual harassment: A research analysis and agenda for the 1990s," Journal of Vocational Behavior 42(1): 5-27.

Lipson, J. 2001. "Hostile hallways: Bullying, teasing, and sexual harassment in school," American Journal of Health Education 32: 307-9.

Population Council. 2011. "Survey of young people in Egypt." Final Report. Cairo: Population Council.

Powell, G. 1983. "Sexual harassment: Confronting the issue of definition," Business Horizons 26(4): 24-28.

Ragab, A.R. 2009. Sexuality Education Approaches: What Would Be Applicable to North of Africa and Middle East? Cairo: AlAzhar University.

Rowe, M.P. 1996. "Dealing with harassment: A systems approach," in Margaret S. Stockdale (ed.) Sexual Harassment in the Workplace: Perspectives, Frontiers, and Response Strategies, Volume 5. Sage Publications, pp. 241-271.

Stillman, T., N. Yamawaki, R. Ridge, P. White, and K. Copley. 2009. "Comparing predictors of sexual harassment proclivity between Japanese and US Men," Psychology of Men \& Masculinity 10(1): 30-43.

Timmerman, G. and C. Bajema. 1999. "Incidence and methodology in sexual harassment research in Northwest Europe," Women's Studies International Forum 22(6): 673-681. 

